\title{
Frontiers in socio-environmental research: components, connections, scale, and context
}

\author{
$\underline{\text { Simone Pulver }}^{1}$, Nicola Ulibarri $^{2}$, Kathryn L. Sobocinski $^{3,4}$, Steven M. Alexander $^{5,6,7}$, Michelle L. Johnson $^{8}$, Paul F. McCord $^{9}$ \\ and Jampel Dell'Angelo ${ }^{10}$
}

\begin{abstract}
The complex and interdisciplinary nature of socio-environmental (SE) problems has led to numerous efforts to develop organizing frameworks to capture the structural and functional elements of SE systems. We evaluate six leading SE frameworks, i.e., human ecosystem framework, resilience, integrated assessment of ecosystem services, vulnerability framework, coupled human-natural systems, and social-ecological systems framework, with the dual goals of (1) investigating the theoretical core of SE systems research emerging across diverse frameworks and (2) highlighting the gaps and research frontiers brought to the fore by a comparative evaluation. The discussion of the emergent theoretical core is centered on four shared structuring elements of SE systems: components, connections, scale, and context. Cross-cutting research frontiers include: moving beyond singular case studies and small-n studies to meta-analytic comparative work on outcomes in related SE systems; combining descriptive and data-driven modeling approaches to SE systems analysis; and promoting the evolution and refinement of frameworks through empirical application and testing, and interframework learning.
\end{abstract}

Key Words: components; connections; context; coupled human and natural systems; ecosystem services; frameworks; human environment; resilience; scale; social-ecological systems; socio-environmental systems; vulnerability

\section{INTRODUCTION}

Socio-environmental(SE) research is one of the most critical areas of investigation and knowledge production on the current and future global scientific agenda (Kates et al. 2001, Liu et al. 2015, Turner et al. 2016). A major challenge of SE research is that socioenvironmental problems by definition span disciplines and thus require a new mode of inquiry distinct from the disciplinary approach dominant in most areas of contemporary research (Max-Neef 2005). To address this challenge, frameworks for SE research have emerged as important conceptual maps. Although the roots of SE scholarship can be traced back to the 1800s, when Thomas Malthus, Karl Marx, George Perkins Marsh, and others put forward theories describing the interdependencies of societies and resource systems (Kates 1987), the past two decades have witnessed a new phase of theoretical development, marked by a proliferation of frameworks for SE research (Binder et al. 2013).

Socio-environmental frameworks assist scholars and practitioners to analyze the complex, nonlinear interdependencies that characterize interactions between biophysical and social arenas and to navigate the new epistemological, ontological, analytical, and practical horizons of integrating knowledge for sustainability solutions. Frameworks are defined broadly as providing "a set of concepts, values and practices that constitute the way of viewing the specific reality" (Binder et al. 2013:2). Along with theories and models, frameworks are the kind of conceptual category whose meaning varies across disciplines (Cox et al. 2016). We use framework to indicate a basic conceptual configuration of ideas; more systematic than an approach but not as well defined as a template. In our usage, frameworks attempt to push research beyond disciplinary boundaries while maintaining a coherent conceptual and analytical system of references. They direct which aspects are simplified and which are detailed, which in turn shapes the research questions, theory, and overall understanding of how SE systems function. Socio-environmental frameworks vary in their disciplinary origins, in their conceptualizations of SE systems, in the purposes for which they were developed, and in their application to empirical cases. However, taken in aggregate, the frameworks and their empirical applications constitute the core of contemporary SE research. The goal of our analysis is to characterize this core through an in-depth comparative assessment of six leading SE frameworks. The analysis both leverages the extensive bodies of research on each of the individual frameworks and extends the nascent literature comparing across SE frameworks.

To date, most SE scholarship has sought to advance the theoretical development or empirical application of a single framework (e.g., Folke et al. 2010, resilience; Alberti et al. 2011, coupled human and natural systems; Bots et al. 2015, social-ecological systems framework). Mostly missing from the SE literature are studies attempting comparative assessments across multiple frameworks. Schlüter et al. (2012) initiated a comparative research agenda with a review of coupled social-ecological systems modeling efforts across the natural resource management, ecological economics, and adaptive systems domains. Their goal was to develop the field of SE systems modeling. The article's conclusion calls for developing a shared framework for conceptualizing and modeling SE systems. In contrast, Binder et al.'s (2013) comparative analysis of 10 established SE frameworks aimed to develop a classification

\footnotetext{
${ }^{1}$ Environmental Studies, University of California, Santa Barbara, ${ }^{2}$ Department of Urban Planning and Public Policy, University of California, Irvine, ${ }^{3}$ College of Earth, Ocean, and Atmospheric Sciences, Oregon State University, ${ }^{4}$ Long Live the Kings, under contract to NOAA-Northwest Fisheries Science Center, ${ }^{5}$ National Socio-Environmental Synthesis Center, University of Maryland, ${ }^{6}$ Stockholm Resilience Centre, Stockholm University, ${ }^{7}$ Environmental Change and Governance Group, University of Waterloo, ${ }^{8}$ Northern Research Station, USDA Forest Service, ${ }^{9}$ Center for Systems Integration and Sustainability, Michigan State University, ${ }^{10}$ Department of Environmental Policy Analysis, Institute for Environmental Studies (IVM), VU University Amsterdam, The Netherlands
} 
system, designed to help users identify the framework most appropriate for their objectives. They catalogued how each framework conceptualized the social and ecological subsystems of SE systems, the dynamics driving each subsystem, the interactions between them, and the relative emphasis of each framework on the social versus ecological subsystem. More recent comparative efforts assessed the current state of theory and empirical knowledge about human stress on the environment and human responses to that stress from five disciplinary perspectives (Cox et al. 2016) and across four SE frameworks (Dietz 2017).

Our project builds most directly on Binder et al. (2013), continuing their effort to characterize the portfolio of research approaches that explicitly consider the interactions between social and environmental systems. Moving beyond Binder et al.'s classification of frameworks but eschewing the attempt to develop a single shared framework, we identify commonalities and divergences across six leading SE frameworks with the dual goals of: (1) characterizing the features of an emergent theoretical core of SE scholarship; and (2) identifying research frontiers highlighted by the differences across the frameworks.

\section{METHODS}

Our analysis is based on a comparison of six distinct frameworks used to guide SE research. They include: the human ecosystem framework (HEF, Machlis et al. 1997), the resilience approach (Resilience, Carpenter et al. 2001, Gunderson and Holling 2001, Holling 2001, Folke 2006), the integrated assessment of ecosystem services approach (IAES, de Groot et al. 2002, MEA 2005), the vulnerability framework (TVUL, Turner et al. 2003), the coupled human-natural systems approach (CHNS, Liu et al. $2007 a, b$ ), and the social-ecological systems framework (SESF, Ostrom 2007, 2009). The abbreviations serve to clearly distinguish between the six frameworks, but it is worth noting that some of the abbreviations, including TVUL and SESF, are not commonly used by the scholars working within the respective research traditions.

A purposive sampling strategy was used (Teddlie and Yu 2007); the frameworks were selected to reflect the diversity of approaches that theorize and address SE problems. We included frameworks that have informed research initiatives (e.g., SESF developed by the Ostrom Workshop and CHNS adopted by the U.S. National Science Foundation) and policy agendas (e.g., IAES tied to the Millennium Ecosystem Assessment). Some frameworks are more conceptual (e.g., Resilience) and others more procedural (e.g., SESF). They have been applied to both rural and urban settings and extend to a range of environmental problem types, ranging from common-pool resource problems (e.g., SESF) to environmental challenges associated with global commodity chains (e.g., CHNS). Finally, each of the six frameworks is either widely used and/or captures a particularly novel aspect of the structure or function of SE systems.

For each framework, we identified a foundational article or articles that first presented a comprehensive overview of the framework, recognizing that in some cases multiple papers served the purpose of introducing the framework. For example, in the case of SESF, Ostrom (2007 and 2009) could both be considered foundational. Likewise, with respect to Resilience, Carpenter et al. (2001), Gunderson and Holling (2001), and Holling (2001) were all published at the same time, and Folke (2006) has also become a highly cited paper. From the foundational texts, we extracted framework authors' assessments of the epistemological purpose and practical aims of their respective frameworks for SE research. The foundational texts were also used to analyze the scope and geographical focus of empirical applications of each framework. Specifically, citation lists for the foundational article (s) were generated in Web of Science and refined to identify citing articles within the domain of SE research and with empirical applications. The resultant articles were catalogued, based on the domain and geographical location of the SE system under study (see Appendix 1 for additional details).

The next step in the analysis was a comparative evaluation of the six frameworks, as presented in foundational texts and selected empirical applications. Drawing on an inductive, grounded theory approach (Glaser and Strauss 1967), we identified four structuring elements common across the frameworks: components, connections, scale, and context. "Components" are the building blocks that constitute SE systems and are often visualized as boxes in SE system diagrams. Components are a diverse category that may include everything from resource stocks to governance arrangements to cultural norms. Components interact to create the interdependent complexity of SE systems and are crucial to SE system conceptualization because they direct analytic attention. "Connections" describe the ways that individual components interact and/or influence one another. In a visual framework, we can think about connections as the arrows connecting component boxes. Connections are critical for diagnosing SE system function, because it is through interactions that system states change (e.g., a shift from sustainable to unsustainable harvesting levels). By carefully specifying different types of connections and how these connections change over time, researchers acknowledge that processes, not just structures, matter and that systems are dynamic. Our third analytic category, "scale" refers to the spatial and temporal dimensions that are used to measure and study any phenomenon (Turner et al. 1989). Scale is a critical consideration because the complexity of SE systems poses a challenge for the identification of appropriate scales of analysis. "Context" is the fourth comparative category. Unlike Binder et al. (2013) who defined the institutional context of an SE system as the disciplinary environment from which a framework emerged, we identify context as the setting for the SE system under study. Setting context boundaries determines what is included and excluded from the analysis, both across space and time. Of the four comparative categories, the definition and operationalization of context varies the most across the six frameworks. For some frameworks context is considered beyond the scope of analysis, although for others it is a defining feature of a particular SE system.

\section{OVERVIEW OF FRAMEWORKS}

The six different frameworks analyzed all integrate social and environmental systems but differ in their epistemological, analytical, and practical purposes, and in their empirical applications. Table 1 provides a list of the SE frameworks analyzed, the foundational text for each framework, and short statements describing each framework's epistemological purpose, and analytical and practical aims. See Appendix 2 for visualizations of each framework. 
Table 1. Epistemological purpose and analytical aims of socio-environmental (SE) frameworks

\begin{tabular}{|c|c|c|c|}
\hline Framework & Foundational text & Epistemological purpose & Analytical and practical aims \\
\hline $\begin{array}{l}\text { Human ecosystem } \\
\text { framework (HEF) }\end{array}$ & Machlis et al. 1997 & $\begin{array}{l}\text { Provide an interdisciplinary organizing } \\
\text { concept for ecosystems management } \\
\text { (Machlis et al. 1997). }\end{array}$ & $\begin{array}{l}\text { (a) Create an organizing tool for ecosystem } \\
\text { management plans, social impact } \\
\text { assessment, and development of social } \\
\text { indicators; (b) Inform natural resource } \\
\text { agencies' monitoring activities (Machlis et } \\
\text { al. 1997). }\end{array}$ \\
\hline Resilience & $\begin{array}{l}\text { Carpenter et al. 2001, } \\
\text { Gunderson and Holling } \\
2001 \text {, Holling 2001, Folke } \\
2006\end{array}$ & $\begin{array}{l}\text { Stimulate integrative and interdisciplinary } \\
\text { science that investigates the dynamics of SE } \\
\text { systems (Holling 2001). }\end{array}$ & $\begin{array}{l}\text { Conceptualize (a) how to navigate ecosystem } \\
\text { dynamics through social networks, } \\
\text { organizations, institutions, and management } \\
\text { practices; and (b) robustness in relation to } \\
\text { social-ecological systems (Folke 2006). }\end{array}$ \\
\hline $\begin{array}{l}\text { Integrated assessment of } \\
\text { ecosystem services (IAES) }\end{array}$ & $\begin{array}{l}\text { de Groot et al. 2002, } \\
\text { Millennium Ecosystem } \\
\text { Assessment } 2005\end{array}$ & $\begin{array}{l}\text { Standardize comparative analysis of } \\
\text { ecosystem functions, goods, and services (de } \\
\text { Groot et al. 2002). }\end{array}$ & $\begin{array}{l}\text { (a) Identify ecosystem functions and related } \\
\text { goods and services; (b) relate ecosystem } \\
\text { functions with valuation techniques; and (c) } \\
\text { inform integrated cost-benefit analysis (de } \\
\text { Groot et al. 2002). }\end{array}$ \\
\hline $\begin{array}{l}\text { Vulnerability framework } \\
\text { (TVUL) }\end{array}$ & Turner et al. 2003 & $\begin{array}{l}\text { Provide a conceptual framework that } \\
\text { considers the vulnerability of complex } \\
\text { human-environment systems (Turner et al. } \\
\text { 2003). }\end{array}$ & $\begin{array}{l}\text { Inform vulnerability analysis and assessment } \\
\text { coherently with global environmental } \\
\text { change and sustainability science } \\
\text { perspectives (Turner et al. 2003). }\end{array}$ \\
\hline $\begin{array}{l}\text { Coupled human and natural } \\
\text { systems (CHNS) }\end{array}$ & Liu et al. $2007 a, b$ & $\begin{array}{l}\text { Promote a paradigmatic shift that } \\
\text { emphasizes hierarchical coupling of human } \\
\text { and natural systems across spatial, } \\
\text { organizational, and temporal scales (Liu et } \\
\text { al. } 2007 a \text { ). }\end{array}$ & $\begin{array}{l}\text { Build cumulative knowledge by progressively } \\
\text { contextualizing local SE interactions within } \\
\text { expanding spatial, organization, and } \\
\text { temporal scales (Liu et al. } 2007 a \text { ). }\end{array}$ \\
\hline $\begin{array}{l}\text { Social-ecological systems } \\
\text { framework (SESF) }\end{array}$ & Ostrom 2007, 2009 & $\begin{array}{l}\text { Provide a diagnostic approach to } \\
\text { systematically organize, compare, and } \\
\text { accumulate findings regarding common- } \\
\text { pool resource systems (Ostrom 2007). }\end{array}$ & $\begin{array}{l}\text { Provide a general framework that identifies } \\
\text { most important subsystem variables that } \\
\text { influence the likelihood of self-organization } \\
\text { to reach sustainability in social-ecological } \\
\text { systems (Ostrom 2007). }\end{array}$ \\
\hline
\end{tabular}

In terms of epistemological purpose, the frameworks range from providing an organizing concept to a template through which to systematize findings across cases. In terms of analytical and practical aims, the frameworks reflect the goals of their creators, be it to assign monetary values to ecosystem services or to generate knowledge regarding successful self-organization of common property systems. Finally, in terms of empirical applications, the frameworks have been used to inspect a broad range of research domains and geographies, although an emphasis does appear to exist surrounding questions of resource management, sustainability, and vulnerability.

Epistemologically, the different frameworks vary in their ambition to produce generalized knowledge. Resilience and CHNS, for example, work at a fairly abstract epistemological level. They highlight foundational concepts and provide a general theory of change in SE systems. In contrast, TVUL focuses specifically on the problem of vulnerability to hazards. As highlevel epistemological guides, Resilience and CHNS are really a way of framing SE problems. Other frameworks address the problem of organization and accumulation of knowledge. The SESF, IAES, and HEF all provide explicit tools to operationalize the framework, organize findings, accumulate knowledge, and standardize comparative analysis.

Fundamental epistemological differences also shape frameworks' emphases on policy relevance. For example, HEF and IAES explicitly state their policy orientations. The HEF asserts that one of its main objectives is to provide a tool for ecosystem management and natural resource agencies' monitoring activities.
The IAES is presented as a tool that can be used for integrated cost-benefit analysis and to enhance balanced decision making in the field of natural resources governance and conservation. Likewise, TVUL is action-oriented, with the stated aim of diagnosing and overcoming human and ecosystem vulnerability. In contrast, Resilience, CHNS, and SESF emphasize knowledge production.

Finally, differences in epistemological purpose and practical aims are also reflected in the empirical applications of the frameworks. The analysis of citations of foundational articles finds that IAES, TVUL, Resilience, and CHNS' foundational texts have each been cited over 800 times. However, the sheer number of citations says little with respect to a framework's operationalization for empirical analysis. This point was made by Epstein et al. (2013) and Vogt et al. (2015) in reference to the limited empirical application of SESF, and we find the same to be true of all frameworks examined herein. Of all the publications citing the CHNS foundational article, only $3 \%$ operationalize the framework by using it within a particular SE system. Similarly, only $11 \%$ of the publications citing the foundational article for Resilience empirically apply the framework, and of the references made to HEF (Machlis et al. 1997), only 9\% use it outside of a cursory or passing citation.

Focusing on the subset of articles in which frameworks are empirically deployed, the citation analysis revealed a range of SE problem domains and geographies. For example, reflecting its practitioner-oriented development by American researchers, HEF has primarily been applied to resource management and 
urban development questions in the United States. By contrast, researchers empirically employing SESF have done so across broad geographies; these applications, however, have primarily been limited to resource governance questions concerning fisheries, water, and forests, reflecting Elinor Ostrom's scholarly interests in common-pool resources. As might be expected, TVUL has been applied to systems at risk and generally avoids a partiality toward specific locales or a type of risk. For example, TVUL has been used to analyze severe flooding in New Orleans, USA, Haikou, China, and the Amazon delta in Brazil. Other researchers have applied the framework to explain the vulnerability of communities to severe winter weather in Mongolia and the Mediterranean. The CHNS has been applied to a range of coupled systems, primarily in the United States' Midwest and East Asia, reflecting perhaps a bias toward systems near the developers' home institutions and/or their primary research sites.

\section{COMPARATIVE EVALUATION OF FRAMEWORKS}

The six frameworks we analyzed vary dramatically in their epistemological and practical aims and in their empirical applications. However, they all seek to provide a coherent conceptual and analytical framework for SE research. The diversity of approaches underscores the need for an integrative comparative analysis. We examine in turn how each framework identifies SE system components, theorizes connections and scale, and delineates context. The four categories provide a common heuristic for analyzing the six frameworks, highlighting both commonalities and differences. Moreover, the comparative strengths and limitations of each framework serve as the basis for a discussion of frontiers for future SE research.

\section{COMPONENTS}

Components are the building blocks of SE systems, and identifying system components is generally the first analytical step in SE research. What is identified as a component fundamentally structures understanding of the system, both theoretically and empirically, and the six frameworks vary significantly in the emphasis they place on components in general and in which components are explicitly identified to constitute the SE system (see Table 2 for an overview). The uniqueness of components across frameworks is perhaps inevitable because different frameworks were designed to grapple with distinct empirical systems, from local resource exploitation (SESF) to the social and environmental ills associated with global commodity chains (CHNS). Of the frameworks considered, SESF offers the most detailed categorization of the many components and subcomponents researchers might want to consider in an SE system analysis. The SESF identifies eight "tier 1" components in the initial framework (Ostrom 2007, expanded in McGinnis and Ostrom 2014), which are further elaborated into tier 2, 3, and 4 subcomponents; although several of these are better understood as attributes rather than stand-alone components (Nagendra and Ostrom 2014). In contrast, TVUL and IAES avoid subcomponents, focusing respectively, on 12 and 9 primary components. Resilience and CHNS are the least focused on components, instead privileging system connections and dynamics (Holling 2001, Liu et al. 2007b).

Comparing the component elements of the six SE frameworks shows some overlap in what are considered key building blocks of an SE system. Most frameworks (four of the six considered) divide the world into two basic components (the natural or ecological system and the human or social system). The two outlier frameworks are HEF and Resilience. The former explicitly avoids the S-E division, joining ecological and social phenomena into the critical resource component. The resilience literature generally eschews identifying abstract system components, although it is worth noting that empirical applications of resilience research rely on a handful of basic ecological and social variables (Folke 2006).

Beyond the basic social/ecological distinction, other areas of commonality include explicit attention to cultural components (HEF and IAES), the SE system context as a component of the system (SESF and TVUL), and the importance of governance (SESF and HEF). Other components are unique to each framework, reflecting each framework's particular emphasis. For example, a sensitivity component is unique to TVUL (Turner et al. 2003). Likewise ecosystem services are mentioned only in IAES (MEA 2005).

\section{Frontiers}

The comparative description of components in the six SE frameworks brings to the fore several challenges/research frontiers. The frontier related to SE system components that has received the most attention so far is the imbalance in most frameworks across the social-ecological distinction. Frameworks tend to emphasize either the social or ecological side of a system, and on the whole, ecological components are neglected in favor of social components such as institutions, governance, culture, and other social variables (Binder et al. 2013, Rissman and Gillon 2017). The HEF is most explicit in its emphasis on elaborating the social components, describing the framework as a "statement of ecology from a human perspective" (Machlis et al. 1997:348). Likewise, SESF was developed largely to understand community factors related to resource overuse (Vogt et al. 2015). To counterbalance this trend, Epstein et al. (2013) suggested adding ecological rules to give ecological context to SESF and provided an example in their analysis of the Lake Washington ecosystem. More generally, bringing ecological theory, i.e., concepts like succession, keystone species, and regime shifts, into SE frameworks will enhance the ecological sophistication of SE models and is argued will generate better diagnoses of SE system performance (Rissman and Gillon 2017, Marshall et al. 2018).

It is worth noting that not all frameworks are built on the socialecological distinction; raising the question of how framework authors initially identify the building blocks of SE systems. None of the frameworks offers a justification for the specific components that constitute their analytic system. Components included are presented as self-evident. The division of SE systems into social/human and ecological/environmental components offers an instructive example. Although seemingly intuitive, this division goes against decades of scholarship in the humanities that challenges the artificial distinction between nature and society (Cronin 1995). Moreover, SE systems in which technology and the built environment play prominent roles fit uncomfortably in the society-environment distinction because neither technology nor the built environment is easily categorized as uniquely social/ human or ecological/environmental (Graedel and Allenby 1993). Anderies et al. (2016) sought to overcome this challenge with the introduction of coupled infrastructure systems as a unit of 
Table 2. Comparing components in selected socio-environmental (SE) frameworks.

\begin{tabular}{|c|c|c|c|}
\hline Framework & $\begin{array}{l}\text { Visual } \\
\text { depiction of } \\
\text { components }\end{array}$ & Components in foundational text & Emphasis on components \\
\hline $\begin{array}{l}\text { Human ecosystem } \\
\text { framework }\end{array}$ & Boxes & $\begin{array}{l}\text { Two primary components (critical resources and human social system); } \\
\text { critical resources include natural, socioeconomic, and cultural resources; } \\
\text { the human social system includes social institutions, social cycles, and } \\
\text { social order. }\end{array}$ & Medium \\
\hline Resilience & None & No components or subcomponents specified. & Low \\
\hline $\begin{array}{l}\text { Integrated assessment of } \\
\text { ecosystem services }\end{array}$ & Boxes & $\begin{array}{l}\text { Two primary components (ecosystem services and human well-being) } \\
\text { linked by indirect and direct drivers; identify four components of } \\
\text { ecosystem services (regulating, provisioning, cultural, and supporting) and } \\
\text { five components of human well-being. }\end{array}$ & Medium \\
\hline Vulnerability framework & Nested boxes & $\begin{array}{l}\text { Twelve primary components, nine of which are specific to vulnerability; } \\
\text { the sensitivity component is composed of the interactions between human } \\
\text { conditions and environmental conditions; contextual components include } \\
\text { the human influences outside the place and the environmental influences } \\
\text { outside the place. }\end{array}$ & Medium \\
\hline $\begin{array}{l}\text { Coupled human and natural } \\
\text { systems }\end{array}$ & $\mathrm{n} / \mathrm{a}$ & $\begin{array}{l}\text { Two primary components (human and natural); beyond this initial } \\
\text { division, there is no elaborated description of subcomponents. }\end{array}$ & Low \\
\hline $\begin{array}{l}\text { Social-ecological systems } \\
\text { framework }\end{array}$ & Boxes & $\begin{array}{l}\text { Eight tier } 1 \text { components: resource system, resource units, governance } \\
\text { system, actors, interactions and outcomes, which combine to create focal } \\
\text { situations, and two contextual components: related ecosystems, and social, } \\
\text { economic, and political settings; tier } 1 \text { components further subdivided into } \\
\text { tier } 2 \text {, tier } 3 \text {, etc. components. }\end{array}$ & Very high \\
\hline
\end{tabular}

analysis and provide a roadmap for how this might overlay with other theoretical frameworks. Similarly, later iterations of the HEF distinguished between the biotic, physical, and social environments (Grove et al. 2015). Despite these recent advances, an epistemological research frontier would be to explore the consequences of the social-environmental distinction for SE system analysis and sustainability prescriptions.

The variety of constituent components of SE systems across frameworks also raises the more fundamental question of what constitutes a component. Although most of the frameworks start with components, they do not specify what a component is. Components can be anything from rules to people to ecosystem services. The most likely explanation for the diversity of primary components across frameworks is that they reflect the particular goals of the framework authors' research approach and the types of environmental problems driving the research. The SESF is most suited toward single case studies of common-pool systems, which implies a distinct set of components based on the local resource system. A different starting point, such as the integrated patch approach advanced by HEF (Pickett et al. 2001), suggests a different set of foundational components and fosters a different research direction. The HEF shifts the research focus onto comparative analyses of socio-environmental interactions across spatial patches in urban ecosystems.

The variation in primary components across SE frameworks creates barriers for building cumulative knowledge within SE scholarship, making theoretical and empirical synthesis across frameworks a challenge. We identify two responses to this challenge. First, it has been productive for authors of various frameworks to develop a shared vocabulary for common concepts, making explicit areas of overlap and divergence across different SE frameworks (Bots et al. 2015, Cox et al. 2016). Second, cumulative knowledge can be built from an empirical starting point. Much SE research focuses on case studies, and the application of frameworks to case studies is revealing of which components and subcomponents are most central to the framework. For example, although SESF and Resilience are difficult to compare in the abstract, empirical analyses of lake water quality under the two frameworks focus on similar variables. Nagendra and Ostrom's (2014) analysis of urban lake commons in Bangalore characterizes 1 resource system variable, 4 governance system variables, and 1 interaction variable, out of a list of over 40 possible SESF subcomponents. An application of the Resilience framework to the water quality of lakes in Wisconsin focuses on a similar set of ecological and economic variables to describe the system (Carpenter et al. 2001).

A final frontier relates to how components are invoked in SE research. As discussed above, specific components and their function in a particular system will vary. However, comparative and integrative efforts could focus on patterns in how components vary over time or the effects of presence/absence of particular components. The SESF's systematic approach enables scholars working within this framework to assess the effects of the presence/absence of individual or combinations of components on system outcomes (Thiel et al. 2015). Likewise, TVUL gives some attention to how changes in particular components move a system to sustainability versus vulnerability. Cox et al.'s (2016) synthesis work provides a template for such efforts.

\section{CONNECTIONS}

Across the frameworks analyzed (excepting Resilience and CHNS), connections tend to be relatively undertheorized relative to components, underscoring the frameworks' emphasis on structure over process (Lade et al. 2015). Table 3 summarizes the frameworks' visual depictions of connections, as well as the types of connections considered and discussed. 
Table 3. Comparing connections in selected socio-environmental (SE) frameworks.

\begin{tabular}{|c|c|c|c|}
\hline Framework & Visual depiction of connections & $\begin{array}{l}\text { Nonlinear or stochastic } \\
\text { connections }\end{array}$ & Feedbacks \\
\hline $\begin{array}{l}\text { Human ecosystem } \\
\text { framework }\end{array}$ & $\begin{array}{l}\text { Arrows depict flows (e.g., of individuals, energy, nutrients). All } \\
\text { component boxes are connected. }\end{array}$ & Not discussed & $\begin{array}{l}\text { Acknowledged in text but } \\
\text { not detailed in analysis }\end{array}$ \\
\hline Resilience & Connectedness as a scalar variable influencing system state. & $\begin{array}{l}\text { Key feature of adaptive } \\
\text { systems, but not depicted as } \\
\text { a connection }\end{array}$ & $\begin{array}{l}\text { Key feature of adaptive } \\
\text { systems, but not depicted as a } \\
\text { connection among } \\
\text { components }\end{array}$ \\
\hline $\begin{array}{l}\text { Integrated assessment } \\
\text { of ecosystem services }\end{array}$ & $\begin{array}{l}\text { Arrows between boxes. Width depicts strength of influence. } \\
\text { Connections flow from the ecosystem to human well-being. }\end{array}$ & $\begin{array}{l}\text { Acknowledged but not in } \\
\text { detail, text only }\end{array}$ & $\begin{array}{l}\text { Feedback from management } \\
\text { to ecosystem structure }\end{array}$ \\
\hline $\begin{array}{l}\text { Vulnerability } \\
\text { framework }\end{array}$ & $\begin{array}{l}\text { Arrows generally mean "lead to" or "affect" (e.g., hazard } \\
\text { consequence). Connections sometimes depicted as boxes (e.g., } \\
\text { an exposure). }\end{array}$ & $\begin{array}{l}\text { Acknowledged but not in } \\
\text { detail, text only }\end{array}$ & Explicit \\
\hline $\begin{array}{l}\text { Coupled human and } \\
\text { natural systems }\end{array}$ & $\mathrm{n} / \mathrm{a}$ & Described in detail & Described in detail \\
\hline $\begin{array}{l}\text { Social-ecological } \\
\text { systems framework }\end{array}$ & $\begin{array}{l}\text { Arrows between boxes. Interactions between variables, typically } \\
\text { using institutional analysis and design (IAD) framework. } \\
\text { Connections may be positive or negative (increase in one } \\
\text { variable leads to increase/decrease in another). Connections } \\
\text { mostly depicted on human side. }\end{array}$ & $\begin{array}{l}\text { Acknowledged but not in } \\
\text { detail, text only }\end{array}$ & $\begin{array}{l}\text { Acknowledged but not } \\
\text { detailed in analysis }\end{array}$ \\
\hline
\end{tabular}

As the table highlights, most of the frameworks visually depict connections as arrows between component boxes. These arrows indicate the direction of influence from one component to another. However, the frameworks overall are not explicit about the currency of the arrows or what they mean. This results in all arrows being treated equally, and therefore the interaction between every pair of components is assumed to be equal. Although in theory, one could imagine that everything might have an influence on every other component of a system, certain interactions matter more for the overall function of that system (Lade et al. 2015). However, the frameworks' visual depictions do not capture such differences in interaction importance.

Some frameworks move beyond the simple depiction of an arrow. Some include a verb or descriptor; for example HEF identifies flows of information, goods, or services with a connection (Grove et al. 2013). Some applications of SESF indicate whether a connection is enhancing or limiting by adding a plus or minus sign (Nagendra and Ostrom 2014). The Millennium Ecosystem Assessment (2005) used arrow width to indicate the strength of the connection. Turner et al. (2003) pushed connections forward by including connections as both arrows and boxes. For instance, an exposure is an interaction between an SE system and a hazard, and therefore a connection that depends on characteristics of existing social and environmental conditions, but it is also a component variable that has its own characteristics (e.g., frequency and magnitude).

In contrast to the other frameworks, CHNS and Resilience emphasize connections over components because their focus is on dynamics and linkages between human and natural systems. Liu et al. (2007a) described many types of connections (or "couplings" in their terminology) that occur between humans and the environment, within and across organizational units, geographies, and times. Although the framework does not necessarily provide conceptual guidance on what the connections are (that depends on the context and questions studied), it does much more than other frameworks to describe the characteristics of connections between human and natural systems. Interestingly, CHNS does not focus as much on connections within either the social or environmental subcomponents as other frameworks, but instead places most emphasis on interactions between the two. Like CHNS, Resilience focuses on connections, but treats them as a variable. Connectedness, or the extent of links between component variables and processes, influences the state of an SE system along the adaptive cycle (Holling 2001). Thus, it does a careful job theorizing what connections do, but does not consider which connections between which variables matter.

\section{Frontiers}

Connections are relatively undertheorized in the original presentations of the SE frameworks analyzed herein. Unlike components, the frameworks mostly do not articulate the types or characteristics of connections one might expect to see in different SE systems. This provides many opportunities for researchers to elaborate what they mean by connections and how connections affect overall system function. First, connections are the entry point for viewing SE systems as complex adaptive systems, depicting the emergent properties, nonlinearity, path dependency, and feedback loops they often display (Becker 2012). As noted in Table 3, most authors acknowledge that components within the system may interact in complex, nonlinear ways and that there are feedbacks that may shift system states. However, these nuances do not tend to appear in the analysis or application of the framework, or even in its depiction at times (Larrosa et al. 2016 made a similar observation). Connections are instead treated as predictable, linear, and not stochastic in most applications. The notable exceptions are CHNS, which discusses in detail how connections change over time, across space, and across varied contexts (e.g., rural versus urbanized settings) and emphasizes the nonlinearity of these interactions (Liu et al. 2007a, $b$ ) and recent work quantifying ecological and social drivers of unexpected shifts in ecosystems (Fillbee-Dexter et al. 2018). 
A frontier is thus used to elaborate what scholars mean by a connection beyond X interacts with Y. Recent theoretical work in this domain is pushing the boundaries of what connections entail. Larrosa et al. (2016) provided a typology of unintended feedbacks, highlighting that through feedbacks the strength of a connection may change, or a connection may even be added to or deleted from a system. In an application of SESF, Cox (2014) used the institutional analysis and development (IAD) framework approach to describe connections between component variables. Cox analyzed connections occurring primarily on the social side, but nevertheless this work represents a much more thorough treatment of connections than is typical of work within SESF.

Recent methodological advances have likewise begun to disaggregate where connections are occurring within a system and what that means for system function. Such advances have the potential to improve SE framework representations of connections (e.g., Zeigler et al. 2017). System dynamics modeling can be used to capture dynamic, nonlinear, and multidirectional interactions. For instance, Lade et al. (2015) modeled interactions between social dynamics and ecological regime shifts, and Anderies (2015) developed mathematical applications of SESF to map fishery sustainability. Network analysis has been used extensively both on the ecological and social sides; for example to model food webs (Dunne et al. 2002) or to assess how individuals and/or social institutions interact (Alexander et al. 2015, Bodin et al. 2017, Ulibarri and Scott 2017) and exchange resources or information (Barnes et al. 2016, Alexander et al. 2017) in managing the environment. The technique is now expanding to include environmental variables within the network, such as harvested species (Bodin et al. 2014) and habitat patches (Sayles and Baggio 2017). Finally, mixed method analyses can assess connections across numerous social and environmental variables and over time. Enfors (2013) used diverse sources, including interviews, land-cover data, and field experiments to model the dynamics within a climate and economy-driven poverty trap in Tanzania and test an approach to redirect the trajectory.

An additional frontier is articulating the characteristics of connections to neighboring SE systems and the consequences of those connections for the core SE system. We know that SE systems do not exist in a vacuum, and that connections between neighboring SE systems can drastically affect function. For example, research at the land-sea interface grapples with linking diverse ecological and governance systems (e.g., Pittman and Armitage 2017). Likewise, the field of landscape ecology considers the influence of adjacent and nearby patches; landscape ecologists have applied the concept of circuitscapes to conceptualizing and modeling flows across patches within a landscape (Pelletier et al. 2017). As with nonlinear dynamics, most of the frameworks acknowledge in the abstract that these crosssystem connections occur but rarely address them in empirical applications of the framework.

\section{SCALE}

Scale in SE frameworks most commonly refers to spatial or temporal dimensions and the recognition that events beyond the local and present may affect SE system outcomes. The visualization and treatment of spatial and temporal scale varies across the six frameworks analyzed, with spatial scale generally receiving more attention than temporal scale. However, all of the frameworks draw some attention to the importance of scale within the text of the foundational papers and acknowledge multiscale interactions (Table 4).

An examination of the six frameworks reveals heterogeneity with regard to their articulation and use of spatial scale. At one end of the spectrum are the frameworks developed for considering placebased problems, e.g., SESF, which emphasizes the importance of identifying and bounding the focal, local SE system (Ostrom 2007). Others use a hierarchical and nested approach to connect SE systems to multiple spatial scales, e.g., Turner et al.'s (2003) use of place, region, world or the Millennium Ecosystem Assessment (2005) use of local, regional, world. More process-based frameworks such as Resilience and CHNS place equal emphasis on factors operating at proximate and distal scales. The CHNS approach in particular focuses on telecoupling, i.e., the connection of spatially distant ecosystems and communities via a range of social (e.g., financial markets) and biophysical processes (e.g., greenhouse gas emissions), deeming them critical to investigations of topics such as climate change adaptation (e.g., Morton 2007, Liu et al. 2013).

Attention to temporal scale is equally varied across the six frameworks. For example in SESF, the temporal dimensions of governance, ecological, and social components are generally underdeveloped. McCord et al. (2016) offered a notable exception. They examined the effects of changes over time in water governance institutions, combining SESF and the Ostrom institutional analysis and development framework. The combination enables analysis of SESF components over time, capturing the temporal dimension through institutional variation. Likewise, TVUL is underdeveloped in the explicit consideration of temporal scale. The foundational article (i.e., Turner et al. 2003) groups temporal scale with spatial scale as spatiotemporal. However, the treatment of temporal scale remains at the system level. The framework misses the opportunity to represent different component variables that may be operating at different temporal scales. In contrast to SESF and TVUL, Resilience, with its emphasis of process over structure, pays careful attention to temporal scale. Resilience focuses on dynamic changes within a system over time, as well as the speed of these changes. Holling (2001) described an "adaptive cycle," characterized by processes of slow change during resource exploitation and resource conservation, followed by rapid transitions marking system reorganization.

Resilience is also unique in its dual emphasis on both spatial and temporal scale, whereas most frameworks privilege one or the other. Although visualizations of the adaptive cycle do not overtly depict spatial scale, it is a key part of the Resilience approach. The term "panarchy" used in Holling (2001) refers to adaptive cycles that take place over space and time. The author gives an example of a forest fire to describe how the speed (i.e., temporal scale) of system change fluctuates as the fire spreads to a broader area (i.e., spatial scale). Spatial and temporal scale are also somewhat developed in CHNS. Liu et al. (2007a) emphasized the spatial and temporal cross-scalar nature of some SE problems, such as the cumulative effect of local greenhouse gas emissions on global climate change.

Recognition of cross-scale interactions and the varying speeds of these interactions is critical to research on complex adaptive SE 
Table 4. Comparing scale in selected socio-environmental (SE) frameworks.

\begin{tabular}{|c|c|c|c|c|}
\hline Framework & Visual depiction of scale & Scale in foundational text & Number of scales & $\begin{array}{l}\text { Cross-scale } \\
\text { connections }\end{array}$ \\
\hline $\begin{array}{l}\text { Human ecosystem } \\
\text { framework }\end{array}$ & $\begin{array}{l}\text { Spatial and temporal scales } \\
\text { not explicit. }\end{array}$ & $\begin{array}{l}\text { Understanding the components of human } \\
\text { ecosystems relies on the description of the } \\
\text { spatial and temporal scales at which these } \\
\text { components occur. }\end{array}$ & $\begin{array}{l}\text { Multiple scales } \\
\text { suggested by text. }\end{array}$ & $\begin{array}{l}\text { Acknowledged in } \\
\text { conceptual diagram } \\
\text { but not detailed in } \\
\text { analysis. }\end{array}$ \\
\hline Resilience & $\begin{array}{l}\text { Spatial scale not explicit; } \\
\text { temporal scale articulated } \\
\text { with use of differently sized } \\
\text { arrows. }\end{array}$ & $\begin{array}{l}\text { Evolving complex adaptive systems of } \\
\text { nature, humans, and human-nature } \\
\text { couplings are interlinked in a hierarchical } \\
\text { structure that is temporally infinite in its } \\
\text { cycles of growth, accumulation, } \\
\text { restructuring, and renewal. }\end{array}$ & $\begin{array}{l}\text { Infinite scales } \\
\text { suggested by text. }\end{array}$ & $\begin{array}{l}\text { Explicitly } \\
\text { acknowledged in } \\
\text { diagram, text, and } \\
\text { analysis. }\end{array}$ \\
\hline $\begin{array}{l}\text { Integrated assessment of } \\
\text { ecosystem services }\end{array}$ & $\begin{array}{l}\text { Spatial scale explicit, via } \\
\text { local, regional, and global } \\
\text { categories. Temporal scale } \\
\text { explicit with short and long } \\
\text { arrows. }\end{array}$ & $\begin{array}{l}\text { Interactions between changing ecosystems } \\
\text { and the services they provide to humans can } \\
\text { occur at one scale or cross-spatial and } \\
\text { temporal scales. }\end{array}$ & $\begin{array}{l}\text { Multiple scales } \\
\text { suggested by text. }\end{array}$ & $\begin{array}{l}\text { Acknowledged in text } \\
\text { but not detailed in } \\
\text { analysis. }\end{array}$ \\
\hline Vulnerability framework & $\begin{array}{l}\text { Spatial scale explicit, via } \\
\text { place, region, and world } \\
\text { categories; temporal scale } \\
\text { loosely depicted with } \\
\text { arrows. }\end{array}$ & $\begin{array}{l}\text { The vulnerability of a particular system is } \\
\text { influenced by the connections operating at } \\
\text { different spatial and temporal scales as well } \\
\text { as the feedbacks across the scales. }\end{array}$ & $\begin{array}{l}\text { Multiple scales } \\
\text { suggested by text. }\end{array}$ & $\begin{array}{l}\text { Acknowledged in } \\
\text { conceptual diagram } \\
\text { but not detailed in } \\
\text { analysis. }\end{array}$ \\
\hline $\begin{array}{l}\text { Coupled human and natural } \\
\text { systems }\end{array}$ & $\mathrm{n} / \mathrm{a}$ & $\begin{array}{l}\text { Couplings between the human and natural } \\
\text { systems occur across nested spatial scales } \\
\text { and at different paces or speeds. }\end{array}$ & $\begin{array}{l}\text { Multiple scales } \\
\text { suggested by text. }\end{array}$ & Described in detail. \\
\hline $\begin{array}{l}\text { Social-ecological systems } \\
\text { framework }\end{array}$ & $\begin{array}{l}\text { Spatial scale not explicit; } \\
\text { temporal scale loosely } \\
\text { represented with arrows. }\end{array}$ & $\begin{array}{l}\text { Described as the multiple nested tiers and } \\
\text { temporal periods of a complex system that } \\
\text { must be understood if sustainable and } \\
\text { unsustainable outcomes are to be identified. }\end{array}$ & $\begin{array}{l}\text { Multiple scales } \\
\text { suggested by text. }\end{array}$ & $\begin{array}{l}\text { Acknowledged in } \\
\text { conceptual diagram } \\
\text { but not detailed in } \\
\text { analysis. }\end{array}$ \\
\hline
\end{tabular}

systems (Liu et al. 2007b, An 2012). By acknowledging that, for instance, small-scale changes can produce unexpected outcomes at the broader system level, framework architects account for emergent properties and other traits characteristic of complex adaptive systems. Perhaps unsurprisingly, nearly all of the foundational papers made reference to complexity theory in introducing their analytical tools. For example, TVUL conceptualizes "vulnerability" within a particular location and nests this location within a broader region as well as a broader global environment. Responses to changes made at the location in question are considered across scales, as are alterations to the physical and social environments. However, of the six reviewed frameworks, Resilience and CHNS give topics such as emergence and aggregation effects (i.e., macroscale phenomena that result from microscale interactions) the most detailed attention. Resilience is perhaps most explicit in its treatment of emergence because it recognizes that adaptive processes produce new outcomes, whereas CHNS emphasizes the role of SE interactions at the local level in producing broad-scale phenomena.

\section{Frontiers}

An evaluation of the six frameworks brings to light several challenges and promising frontiers related to scale. These include greater attention to temporal scale, including the potential differences between social and ecological variables when it comes to temporal scale. More broadly, deeper reflection is merited on strategies to effectively incorporate and link spatial and temporal scale, theoretically and empirically. Multiscale interactions dominate SE systems (Holling 2001), and insufficient attention to multiple scales may lead scholars to erroneously focus on one scale of analysis when, in fact, many are relevant (Cash et al. 2006).

A review of the literature further suggests that both telecoupling and decoupling present research frontiers related to scale. As global interconnectedness increases (Mehta et al. 2012, Rulli et al. 2013, Dell'Angelo et al. 2018), the understanding of distal spatial and temporal linkages and their influence on SE systems becomes evermore important. However, there remains a dearth of empirical work on telecoupling and its implications for SE systems (Hull et al. 2015, Pace and Gephart 2017). As a first step, Prell et al. (2017) provided an elegant empirical example that identifies spatially distant feedback loops in global trade through an innovative approach that combines network modeling and input-output analysis. Likewise, Lenshwow et al. (2016) highlighted the particular challenges of governance associated with telecoupling in SE systems, whereas Liu et al. (2016) employed the telecoupling concept to understand resource flows, in the form of water transfers, across vast distances.

Although the majority of SE research focuses on the linkages between social and ecological systems, it must be acknowledged that SE systems can also undergo processes of decoupling. For example, technological innovation may reduce community dependence on local ecosystem services, thus partially decoupling linkages between human well-being and surrounding ecosystems (Raudsepp-Hearne et al. 2010). Likewise, policy interventions may seek to force decoupling. In many natural resource-based systems, such as rangelands and forests, policies have sought to 
separate herders or forest users from the systems they manage (Hoole and Berkes 2010, Li and Li 2012). Both forms of decoupling are considered in the CHNS and Resilience frameworks but deserve wider attention.

A final research frontier related to scale in SE systems reflects the heavy reliance in much scale-related research on single case studies. Multicase comparative assessments that rely on findings from a collection of scientific investigations of scale advance this research frontier. One such example of multicase comparative SE research is Rocha et al. (2015) in which 13 marine regime shifts were investigated to understand the multiscalar drivers of these shifts. Similarly, van Vliet et al. (2016) conducted a review of landuse science meta-studies to assess the multiscalar processes producing deforestation, agricultural, and urbanization outcomes. Both studies allow for broader generalizing about the relationship between scale and SE sustainability outcomes.

\section{CONTEXT}

Context is the final comparative category and is defined as the setting of an SE system. In conceptual framework diagrams, there is sometimes a box or boundary around an SE system, and what lies beyond this boundary is defined as context. It is worth noting that context is tightly intertwined with scale. System context is constituted by the system elements that operate at spatial or temporal scales defined as beyond the system of study. The selection of the spatial and temporal scales for a system thus defines the information analyzed for context. Across the SE frameworks analyzed, context varies in the degree to which there is a clear boundary between the system and its context, if this boundary is static or dynamic, and if and what aspects of context merit analytical attention (Table 5).

Only SESF and TVUL include context as an explicit aspect of the framework. Resilience and CHNSleave context implicit. The SESF defines context as the larger socioeconomic, political, and ecological setting surrounding the SE system under study (Ostrom 2007, 2009). With its emphasis on place-based analysis, TVUL identifies a need to consider the system context, while noting that analyzing the totality of a system's context is unrealistic (Turner et al. 2003). Indeed, this trade-off between generalizability and context-dependence may be why context is not explicit in Resilience, HEF, CHNS, and IAES. However, context does appear in empirical applications of these frameworks. For example, Carpenter et al. (2001) used a Resilience approach to compare lake district and rangeland systems, noting similarities (e.g., governance structures) and differences (e.g., regional climate) across each SE system's context.

Definitions of system boundaries also differ across the selected frameworks. The SESF, TVUL, and HEF are place-based in focus, which should allow a system boundary to be more readily defined. For example, a system boundary is explicitly mentioned as a requisite for HEF (Pickett et al. 2001). However, the nestedness of systems in TVUL and links across systems in SESF also create a challenge in identifying a clear system boundary. Other frameworks do not include a clear boundary, perhaps because of the cross-scalar nature of some connections between components related to ecosystem services (e.g., global trade) in the case of IAES, because of the framework's emphasis on generalizable principles of SE systems in the case of Resilience, and because of the teleconnections among larger systems in CHNS
Frameworks vary in their assessments of context as either relevant to or beyond the scope of analysis. For example, because hazards can occur both within and outside the place of assessment, TVUL takes a dynamic approach to context. A changing context can change the system of study and the system of study can change the context. Other frameworks take a more static approach to context. The SESF conceptualizes context as "the encompassing variables that remain constant for a given study but not across studies" (Agrawal 2003:251), defining context as that which is static for a particular study site. Likewise, HEF, with its watershed approach, focuses more on what is inside the boundary than how the focal SE system is linked to other systems. For frameworks that leave context implicit and do not establish a system boundary, like Resilience and IAES, the relationship between a system and its context is unclear; only empirical applications of the frameworks can highlight how context is considered, and these outcomes depend upon how researchers interpret and adapt the framework.

Most frameworks include some mention of temporal context. For example, Resilience theory emphasizes the path-dependent nature of systems, implying that historical context is important to understand an SE system and its trajectory. Likewise, TVUL recognizes that a system's risk to future hazards is dependent on its past risk exposure. With its emphasis on the ecology of cities and patch dynamics, HEF also considers cycles of individuals, institutions, and the environment that note the importance of historical conditions, including land-use history and cultural myths and beliefs. Other frameworks, such as SESF, focus more on present-day settings as context, although a description of local and regional histories are a consistent element of empirical case studies applying SESF (e.g., Cox 2014, Nagendra and Ostrom 2014).

\section{Frontiers}

There is progress to be made in defining and describing context in SE frameworks. A first research frontier relates to the setting of boundaries implied by the term context. The boundaries of SE systems are increasingly recognized as porous, rather than fixed. In looking at urban SE systems, McHale et al. (2013) pointed to the diffuseness of urban systems, as they extend into suburbs and the wildland-urban interface. In addition, social and ecological boundaries often do not align. For example, there may be several social systems operating within the realm of one ecosystem (Thomas 2017) or the drivers of system change in ecological systems may extend far beyond the boundaries of the social system (Chapin et al. 2006). As a first step, these challenges in defining boundaries could be reflected in SE framework conceptual diagrams in which exchange between what is inside and what is outside a system can be more explicitly indicated. More broadly, defining context may be better done in a hierarchical fashion, in which multiple scales of influence are used to distinguish between core and ancillary aspects of systems, generating a multidimensional definition of context. The SESF considers nestedness, but currently emphasizes the nestedness of attributes, not systems within contexts (see Cox 2014). The CHNS and Resilience frameworks may be the most developed in terms of capturing system nestedness because they recognize that SE systems can be analyzed in progressively expanding contexts, extending to more encompassing spatial and temporal scales. 
Table 5. Comparing context in selected socio-environmental (SE) frameworks

\begin{tabular}{|c|c|c|c|c|}
\hline Framework & Visual depiction of context & $\begin{array}{l}\text { Context in } \\
\text { foundational text }\end{array}$ & Focal aspects of context & Static/Dynamic \\
\hline $\begin{array}{l}\text { Human ecosystem } \\
\text { framework }\end{array}$ & $\begin{array}{l}\text { Clear boundary, but no description of } \\
\text { what is outside boundary }\end{array}$ & Implicit & Social and land-use history & Static \\
\hline Resilience & Not in diagram & Implicit & Past system states & Unclear \\
\hline $\begin{array}{l}\text { Integrated assessment of } \\
\text { ecosystem services }\end{array}$ & Not in diagram & Implicit & Factors affecting valuation & Unclear \\
\hline Vulnerability framework & $\begin{array}{l}\text { Clear boundary, and text naming } \\
\text { human and environmental influences } \\
\text { outside the place }\end{array}$ & Explicit & Factors affecting hazards & Dynamic \\
\hline $\begin{array}{l}\text { Coupled human and } \\
\text { natural systems }\end{array}$ & $\mathrm{n} / \mathrm{a}$ & Implicit & $\begin{array}{l}\text { Organizational, temporal, and spatial } \\
\text { couplings of human and natural systems }\end{array}$ & Dynamic \\
\hline $\begin{array}{l}\text { Social-ecological systems } \\
\text { framework }\end{array}$ & $\begin{array}{l}\text { Clear boundary, and text naming } \\
\text { social, economic, and political settings, } \\
\text { as well as related ecosystems }\end{array}$ & Explicit & $\begin{array}{l}\text { Social, economic, political, and } \\
\text { ecological setting }\end{array}$ & Static \\
\hline
\end{tabular}

More generally, research is needed to address the tension between context as beyond the scope of an SE system analysis versus context as a key feature of a particular system (Thiel et al. 2015). Because problem framing affects the specificity of context, there is no one set definition of context applicable to all SE frameworks. How a system is conceptualized will affect if and what aspects of a system's setting are relevant to a particular framework. A second research frontier thus relates to comparative studies of context. Making context the explicit focus of comparative empirical analysis, within and across frameworks, would clarify if, when, and how context contributes to system outcomes. Kittinger et al. 's (2013) discussion of external drivers of change in small-scale fisheries provides a compelling example. It is often only in the empirical application of a framework that context is operationalized. As Liu et al. (2007b) pointed out, the empirical application of a framework is context dependent, and thus, context is clarified when working in a particular setting to better understand the set of pre-existing conditions that creates the problem in question.

Finally, context across time merits equal attention to context across space. The importance of historical/evolutionary context within social science and ecological research seems almost selfevident, but somehow it is often ignored in SE research. History is given some attention across the six frameworks analyzed, but a more systematic approach is needed. In the ecological context, this would take the form of geological or evolutionary history, whereas in the social domain it would be political, social, and economic histories that converge. In combination, these historical contexts define the components and connections in any particular $\mathrm{SE}$ system and constrain future trajectories. With the growing awareness of and research emphasis on global change, understanding SE systems in a dynamic, evolutionary context, with trajectories constrained by path dependence becomes increasingly important (Carpenter and Rissman 2012).

\section{DISCUSSION AND CONCLUSIONS}

Considering the interdisciplinary nature that characterizes the field of study focused on human-environment interactions, the plethora of conceptual frameworks and theories that have emerged should come as no surprise. This review was based on an in-depth comparative analysis of six leading conceptual frameworks guiding current and future SE research to explore the emergent theoretical core of SE scholarship, as well as to identify key gaps and associated frontiers in SE research. The strength of our approach is to promote linkages and shared understanding across diverse SE research communities. It moves in the direction of strengthening the inter- and trans-disciplinary shifts that characterize SE research and is complementary to other review strategies based on methodological approaches or empirical research. The latter are better suited to an assessment of the current state of knowledge about interactions between social and environmental systems, whereas our approach contributes broadly to theoretical and conceptual developments. In particular, our analysis identifies three features of an emergent theoretical core in SE research and three crosscutting conceptual/ methodological frontiers.

Emergent theoretical core of socio-environmental (SE) research The first core feature across scholarship in this arena is the premise of a social-environmental (or social-ecological or human-natural) distinction. Although there have been some challenges to this distinction from the humanities and HEF, it remains an organizing principle for SE research, reflecting the disciplinary communities and types of knowledge that SE scholarship seeks to unite. Given the shared commitment to this distinction, it is the responsibility of the SE community to give due consideration to both parts of the system. Although in any particular application of these frameworks, the social and ecological elements of the system may not be equally important or wellunderstood, responsible practice requires that analysts consider social and ecological contributions at least as potentially of equal importance.

The second core feature is that components, connections, scale, and context play central roles in SE systems. These four categories emerge as important to SE system analysis when the six frameworks are considered in aggregate: components as the building blocks that constitute an SE system; the type, directionality, and characteristics of the connections linking components; the ways in which different frameworks grapple with scale, scale mismatch, and cross-scalar interactions; and the different conceptualizations of the contexts surrounding SE systems. Despite significant variation in the relative emphasis and 
elaboration of different foundational elements across SE frameworks, these four foundational elements emerge as central to SE system conceptualization.

The third shared principle relates to the practice of SE research. In particular, trade-offs emerge as a key feature of SE scholarship. Despite the differences among the compared frameworks, each of the frameworks provides effective points of entry in terms of understanding the complexity of SE systems. Our analysis highlights that there are many ways a system can be reduced; however, frameworks that succeed at conceptualizing components do a relatively poor job considering connections and vice versa. Finding a way to combine components and connections, to understand both what the critical components of a system are and how they interact, would strengthen theory of how and why SE systems function as they do and potentially lead to solutions for the complex problems they seek to understand. Likewise, theoretical development and empirical data seem to be inversely related in SE research. There is a trade-off between framework generality in theory and context specificity in application. Complex theoretical frameworks, such as the multitier components in SESF, are significantly simplified when empirical data is collected for a particular case. In contrast, context, which is undertheorized across the frameworks, is often the most empirically detailed element of the case analysis.

Crosscutting conceptual, methodological, and empirical frontiers In addition to tracing the contours of an emergent theoretical core of SE research, the second goal of our analysis was to highlight current gaps and point to frontiers to advance our understanding of SE systems. Research frontiers specific to components, connections, scale, and context were identified. The focus is on overarching conceptual, methodological, and empirical frontiers. At some frontiers, work is already being pursued, while at others, we identify opportunities for innovation.

Aggregation offers a first overarching conceptual/methodological frontier. There is a clear opportunity to move beyond single case studies and small- $n$ studies in SE research. One promising pathway includes meta-analysis of the empirical studies conducted both within and across the different frameworks (e.g., Cox et al. 2010, Fleischman et al. 2014, Huitric et al. 2016). A meta-analysis of empirical applications across frameworks could find overarching categories of what components matter, how connections work, and how the scale of analysis affects what components or connections matter. In particular, we argue that connections and scale lend themselves to more general theorizing. Neither connections nor scale are unique to any one particular SE system, making them more promising for theoretical and conceptual development. However, with the exception of Resilience, the frameworks evaluated do not venture beyond descriptive analysis of connections (e.g., nonlinear, bidirectional, strong/weak, telecoupled, etc.) to offer theories of connections across scales, including how they work, why they matter, when they matter, and how they relate to system states. Resilience offers a promising starting point for investigating multiscalar phenomena and advancing the understanding of temporal connections across physical scales, and it would benefit from critical engagement by other SE frameworks. Methodologies to advance this work include generalized modeling (e.g., Lade et al.
2015) and social-ecological network analysis (e.g., Bodin et al. 2014, Sayles and Baggio 2017).

We also identify unique opportunities for aggregation in the components and context categories. Both components and contexts are mostly unique to individual SE systems. The application of a given framework to an SE research problem necessarily takes a more situational position, i.e., the unique ecological, social, and historical components and context of any problem frames the use and application of a framework. For this reason, comparative studies could be very informative in isolating the unique contributions of context to SE system outcomes. Moreover, aggregation, particularly across frameworks, would help advance common terminology for the same SE system components identified by different approaches.

A second conceptual/methodological frontier relates to "thick" and "thin" approaches (Geertz 1994) to define important SE system elements. A thick approach launches from a descriptive starting point and seeks to capture all the components, connections, cross-scalar interactions, and elements of context that are potentially relevant to SE system outcomes. Such attempts at comprehensiveness are validated by examples in which the exclusion of one system element leads to system crash (e.g., chlorofluorocarbons and stratospheric ozone, Benedick 1998). However, studying the complexity of entire systems can require large teams and time frames, which limits our ability to empirically study SE systems. A thin approach seeks to build understanding from the least number of components and connections needed to analyze a particular system. This type of approach is common in applications that involve some sort of data-driven model. Strategically combining these approaches would lead to the inclusion of only the most important components, connections, and aspects of scale and context, while guarding against unforeseen system dynamics. There is a clear need for methodological advances and novel multimethod approaches to improve our analytical power to allow us to increase the components under consideration, capture more explicitly the connections among and within these components, and integrate scalar interactions and dynamics. However, such a task is not without its challenges and may require exploring emerging approaches for synthesizing across qualitative and quantitative studies (e.g., Dixon-Woods et al. 2005, Enfors 2013).

A third crosscutting conceptual/methodological frontier relates to the constant evolution and refinement of SE framework theorizing. The six frameworks considered have all changed over time, both through learning from empirical application and through incorporating and learning from other frameworks. We identify the need for more empirical applications of SE frameworks because the application itself is where much of the understanding of SE systems is currently occurring. When possible, this should take the form of testing frameworks, at least for those frameworks that generate testable predictions. The utility of this empirical testing can be clearly seen in the evolution of SESF, which has emphasized rigorous, consistent empirical applications of the framework across multiple empirical settings (e.g., Epstein et al. 2013, Cox, 2014, Vogt et al. 2015). More generally, the results of empirical studies can feed into updating frameworks, making them a living repository of SE system structure and function. 
Researchers dealing with complex SE problems address wicked problems (Levin et al. 2012). There are no easy, objective, and clear-cut solutions to these problems yet they are urgent and have strong societal implications. We seek to advance SE scholarship by identifying an emergent theoretical core of SE scholarship and by highlighting research frontiers, all with the greater purpose of enhancing the utility of SE frameworks in resolving the complex socio-environmental problems that they aim to explain, compare, and assess. This question of utility should be at the forefront of continuing development of frameworks and related research.

\section{Responses to this article can be read online at: http://www.ecologyandsociety.org/issues/responses. $\mathrm{php} / 10280$}

\section{Acknowledgments:}

We thank the National Socio-Environmental Synthesis Center (SESYNC) for fostering the Socio-Environmental Immersion Program, where ideas for this work originated. We also thank Olaf Jensen for helpful comments on an earlier draft of the manuscript. SMA was supported by the Social Sciences and Humanities Research Council of Canada and by the National SocioEnvironmental Synthesis Center through NSF Grant \#DBI-1052875.

\section{LITERATURE CITED}

Agrawal, A. 2003. Sustainable governance of common-pool resources: context, methods, and politics. Annual Review of Anthropology 32(1):243-262. http://dx.doi.org/10.1146/annurev. anthro.32.061002.093112

Alberti, M., H. Asbjornsen, L. A. Baker, N. Brozovic, L. E. Drinkwater, S. A. Drzyzga, C. A. Jantz J. Fragoso D. S. Holland T. (Tim) A. Kohler, J. (Jack) Liu, W. J. McConnell, H. D. G. Maschner, J. D. A. Millington, M. Monticino, G. Podestá, R. G. Pontius, Jr., C. L. Redman, N. J. Reo, D. Sailor, and G. Urquhart. 2011. Research on coupled human and natural systems (CHANS): approach, challenges, and strategies. Bulletin of the Ecological Society of America 92(2):218-228. http://dx.doi. org/10.1890/0012-9623-92.2.218

Alexander, S. M., D. Armitage, P. J. Carrington, and Ö. Bodin. 2017. Examining horizontal and vertical social ties to achieve social-ecological fit in an emerging marine reserve network. Aquatic Conservation: Marine and Freshwater Ecosystems 27 (6):1209-1223. http://dx.doi.org/10.1002/aqc. 2775

Alexander, S. M., D. Armitage, and A. Charles. 2015. Social networks and transitions to co-management in Jamaican marine reserves and small-scale fisheries. Global Environmental Change 35:213-225. http://dx.doi.org/10.1016/j.gloenvcha.2015.09.001

An, L. 2012. Modeling human decisions in coupled human and natural systems: review of agent-based models. Ecological Modelling 229:25-36. http://dx.doi.org/10.1016/j.ecolmodel.2011.07.010

Anderies, J. M. 2015. Understanding the dynamics of sustainable social-ecological systems: human behavior, institutions, and regulatory feedback networks. Bulletin of Mathematical Biology 77(2):259-280. http://dx.doi.org/10.1007/s11538-014-0030-z
Anderies, J. M., M. A. Janssen, and E. Schlager. 2016. Institutions and the performance of coupled infrastructure systems. International Journal of the Commons 10(2):495-516. http://dx. doi.org/10.18352/ijc. 651

Barnes, M. L., J. Lynham, K. Kalberg, and P. S. Leung. 2016. Social networks and environmental outcomes. Proceedings of the National Academy of Sciences 113(23):6466-6471. http://dx.doi. org/10.1073/pnas.1523245113

Becker, E. 2012. Social-ecological systems as epistemic objects. Pages 37-59 in M. Glaser, G. Krause, B. M.W. Ratter, and M. Welp, editors. Human-nature interactions in the Anthropocene: potentials of social-ecological systems analysis. Routledge, London, UK.

Benedick, R. E. 1998. Ozone diplomacy. Harvard University Press, Cambridge, Massachusetts, USA.

Binder, C. R., J. Hinkel, P. W. G. Bots, and C. Pahl-Wostl. 2013. Comparison of frameworks for analyzing social-ecological systems. Ecology and Society 18(4):26. http://dx.doi.org/10.5751/ ES-05551-180426

Bodin, Ö., B. Crona, M. Thyresson, A.-L. Golz, and M. Tengö. 2014. Conservation success as a function of good alignment of social and ecological structures and processes. Conservation Biology 28(5):1371-1379. http://dx.doi.org/10.1111/cobi.12306

Bodin, Ö., A. Sandström, and B. Crona. 2017. Collaborative networks for effective ecosystem-based management: a set of working hypotheses. Policy Studies Journal 45(2):289-314. http:// dx.doi.org/10.1111/psj.12146

Bots, P. W. G., M. Schlüter, and J. Sendzimir. 2015. A framework for analyzing, comparing, and diagnosing social-ecological systems. Ecology and Society 20(4):18. http://dx.doi.org/10.5751/ ES-08051-200418

Carpenter, S. R., B. Walker, J. M. Anderies, and N. Abel. 2001. From metaphor to measurement: resilience of what to what? Ecosystems 4:765-781. http://dx.doi.org/10.1007/s10021-001-0045-9

Carpenter, S. R., and A. R. Rissman. 2012. Scenarios and decision making for complex environmental systems. Pages 37-44 in D. N. Bengston, editor. Environmental futures research: experiences, approaches, and opportunities. General technical report NRSP-107. Department of Agriculture, Forest Service, Northern Research Station, Newtown Square, Pennsylvania, USA. [online] URL: https://www.fs.fed.us/nrs/pubs/gtr/gtr nrs-p-107.pdf

Cash, D. W., W. N. Adger, F. Berkes, P. Garden, L. Lebel, P. Olsson, L. Pritchard, and O. Young. 2006. Scale and cross-scale dynamics: governance and information in a multilevel world. Ecology and Society 11(2):8. http://dx.doi.org/10.5751/ES-01759-110208

Chapin, F. S., III, M. Hoel, S. R. Carpenter, J. Lubchenco, B. Walker, T. V. Callaghan, C. Folke, S. A. Levin, K.-G. Mäler, C. Nilsson, S. Barrett, F. Berkes, A.-S. Crépin, K. Danell, T. Rosswall, D. Starrett, A. Xepapadeas, and S. A. Zimov. 2006. Building resilience and adaptation to manage Arctic change. Ambio 35(4):198-202. http://dx.doi.org/10.1579/0044-7447(2006) 35[198:BRAATM]2.0.CO;2

Cox, M. 2014. Applying a social-ecological system framework to the study of the Taos Valley irrigation system. Human Ecology 42(2):311-324. http://dx.doi.org/10.1007/s10745-014-9651-y 
Cox, M., G. Arnold, and S. Villamayor Tomás. 2010. A review of design principles for community-based natural resource management. Ecology and Society 15(4):38. http://dx.doi. org/10.5751/ES-03704-150438

Cox, M., S. Villamayor-Tomás, G. Epstein, L. Evans, N. C. Ban, F. Fleischman, M. Nenadovic, and G. Garcia-Lopez. 2016. Synthesizing theories of natural resource management and governance. Global Environmental Change 39:45-56. http://dx.doi. org/10.1016/j.gloenvcha.2016.04.011

Cronin, W. 1995. Uncommon ground: rethinking the human place in nature. Harcourt Brace, New York, New York, USA.

de Groot, R. S., M. A. Wilson, and R. M. J. Boumans. 2002. A typology for the classification, description and valuation of ecosystem functions, goods and services. Ecological Economics 41(3):393-408. http://dx.doi.org/10.1016/S0921-8009(02)00089-7

Dell'Angelo, J., M. C. Rulli, and P. D'Odorico. 2018. The global water grabbing syndrome. Ecological Economics, 143: 276-285. http://dx.doi.org/10.1016/j.ecolecon.2017.06.033

Dietz, T. 2017. Drivers of human stress on the environment in the twenty-first century. Annual Review of Environment and Resources 42(1):189-213. http://dx.doi.org/10.1146/annurev-environ-110615-085440

Dixon-Woods, M., S. Agarwal, D. Jones, B. Young, and A. Sutton. 2005. Synthesising qualitative and quantitative evidence: a review of possible methods. Journal of Health Services Research and Policy 10(1):45-53. http://dx.doi.org/10.1177/135581960501000110

Dunne, J. A., R. J. Williams, and N. D. Martinez. 2002. Food-web structure and network theory: the role of connectance and size. Proceedings of the National Academy of Sciences 99 (20):12917-12922. http://dx.doi.org/10.1073/pnas.192407699

Enfors, E. 2013. Social-ecological traps and transformations in dryland agro-ecosystems: using water system innovations to change the trajectory of development. Global Environmental Change 23(1):51-60. http://dx.doi.org/10.1016/j.gloenvcha.2012.10.007

Epstein, G., J. M. Vogt, S. K. Mincey, M. Cox, and B. C. Fischer. 2013. Missing ecology: integrating ecological perspectives with the social-ecological system framework. International Journal of the Commons 7(2):432-453. http://dx.doi.org/10.18352/ijc.371

Filbee-Dexter, K., C. C. Symons, K. Jones, H. A. Haig, J. Pittman, S. M. Alexander, and M. J. Burke. 2018. Quantifying ecological and social drivers of ecological surprise. Journal of Applied Ecology. http://dx.doi.org/10.1111/1365-2664.13171

Fleischman, F. D., N. C. Ban, L. S. Evans, G. Epstein, G. GarciaLopez, and S. Villamayor-Tomas. 2014. Governing large-scale social-ecological systems: lessons from five cases. International Journal of the Commons 8(2):428-456. http://dx.doi.org/10.18352/ ijc. 416

Folke, C. 2006. Resilience: the emergence of a perspective for social-ecological systems analyses. Global Environmental Change 16:253-267. http://dx.doi.org/10.1016/j.gloenvcha.2006.04.002

Folke, C., S. R. Carpenter, B. Walker, M. Scheffer, T. Chapin, and J. Rockström. 2010. Resilience thinking: integrating resilience, adaptability and transformability. Ecology and Society 15(4):20. http://dx.doi.org/10.5751/ES-03610-150420
Geertz, C. 1994. Thick description: toward an interpretive theory of culture. Pages 213-231 in M. Martin and L. C. McIntyre, editors. Readings in the philosophy of social science. MIT Press, Cambridge, Massachusetts, USA.

Glaser, B. G., and A. L. Strauss. 1967. The discovery of grounded theory: strategies for qualitative research. Aldine, Chicago, Illinois, USA.

Graedel, T. E., and B. R. Allenby. 1995. Industrial ecology. Prentice Hall, Englewood Cliffs, New Jersey, USA.

Grove, J. M., M. Cadenasso, S. Pickett, G. Machlis, and W. R. Burch, Jr. 2015. The Baltimore school of urban ecology: space, scale, and time for the study of cities. Yale University Press, New Haven, Connecticut, USA. http://dx.doi.org/10.12987/ yale/9780300101133.001.0001

Grove, J. M., S. T. A. Pickett, A. Whitmer, and M. L. Cadenasso. 2013. Building an urban LTSER: the case of the Baltimore ecosystem study and the D.C./B.C. ULTRA-Ex project. Pages 369-408 in S. Singh, H. Haberl, M. M. Chertow, M. Mirtl, and M. Schmid, editors. Long term socio-ecological research studies in society: nature interactions across spatial and temporal scales. Springer. Dordrecht, Germany..

Gunderson, L. H., and C. S. Holling. 2001. Panarchy: understanding transformations in human and natural systems. Island, Washington, D.C., USA.

Holling, C. S. 2001. Understanding the complexity of economic, ecological, and social systems. Ecosystems 4(5):390-405. http:// dx.doi.org/10.1007/s10021-001-0101-5

Hoole, A., and F. Berkes. 2010. Breaking down fences: recoupling social-ecological systems for biodiversity conservation in Namibia. Geoforum 41(2):304-317. http://dx.doi.org/10.1016/j. geoforum.2009.10.009

Huitric, M., G. D. Peterson, and J. C. Rocha. 2016. What factors build or erode resilience in the Arctic? Pages 96-121 in M. Carson and G. Peterson, editors. Arctic resilience report 2016. Stockholm Environment Institute and Stockholm Resilience Centre, Stockholm, Sweden. [online] URL: https://www.dropbox.com/ s/5b6taw7kr9507xn/ARA.pdf?dl=0

Hull, V., M.-N. Tuanmu, and J. Liu. 2015. Synthesis of humannature feedbacks. Ecology and Society 20(3):17. http://dx.doi. org/10.5751/ES-07404-200317

Kates, R. W. 1987. The human environment: the road not taken, the road still beckoning. Annals of the Association of American Geographers 77(4):525-534. http://dx.doi.org/10.1111/j.1467-8306.1987. $\underline{\text { tb00178.x }}$

Kates, R. W., W. C. Clark, R. Corell, J. M. Hall, C. C. Jaeger, I. Lowe, J. J. McCarthy, H. J. Schellnhuber, B. Bolin, N. M. Dickson, S. Faucheux, G. C. Gallopin, A. Grübler, B. Huntley, J. Jäger, N. S. Jodha, R. E. Kasperson, A. Mabogunje, P. Matson, H. Mooney, B. Moore, III, T. O'Riordan, and U. Svedin. 2001. Sustainability science. Science 292(5517):641-642. http://dx.doi.org/10.1126/ science. 1059386

Kittinger, J. N., E. M. Finkbeiner, N. C. Ban, K. Broad, M. H. Carr, J. E. Cinner, S. Gelcich, M. L. Cornwell, J. Z. Koehn, X. Basurto, R. Fujita, M. R. Caldwell, and L. B. Crowder. 2013. 
Emerging frontiers in social-ecological systems research for sustainability of small-scale fisheries. Current Opinion in Environmental Sustainability 5(3-4):352-357. http://dx.doi. org/10.1016/j.cosust.2013.06.008

Lade, S. J., S. Niiranen, J. Hentati-Sundberg, T. Blenckner, W. J. Boonstra, K. Orach, M. F. Quaas, H. Österblom, and M. Schlueter. 2015. An empirical model of the Baltic Sea reveals the importance of social dynamics for ecological regime shifts. Proceedings of the National Academy of Sciences 112 (35):11120-11125. http://dx.doi.org/10.1073/pnas.1504954112

Larrosa, C., L. R. Carrasco, and E. J. Milner-Gulland. 2016. Unintended feedbacks: challenges and opportunities for improving conservation effectiveness. Conservation Letters 9 (5):316-326. http://dx.doi.org/10.1111/conl.12240

Lenschow, A., J. Newig, and E. Challies. 2016. Globalization's limits to the environmental state? Integrating telecoupling into global environmental governance. Environmental Politics 25 (1):136-159. http://dx.doi.org/10.1080/09644016.2015.1074384

Levin, K., B. Cashore, S. Bernstein, and G. Auld. 2012. Overcoming the tragedy of super wicked problems: constraining our future selves to ameliorate global climate change. Policy Sciences 45(2):123-152. http://dx.doi.org/10.1007/s11077-012-9151-0

Li, W., and Y. Li. 2012. Managing rangeland as a complex system: how government interventions decouple social systems from ecological systems. Ecology and Society 17(1):9. http://dx.doi. org/10.5751/ES-04531-170109

Liu, J., T. Dietz, S. R. Carpenter, C. Folke, M. Alberti, C. L. Redman, S. H. Schneider, E. Ostrom, A. N. Pell, J. Lubchenco, W. W. Taylor, Z. Ouyang, P. Deadman, T. Kratz, and W. Provencher. 2007a. Coupled human and natural systems. Ambio 36(8):639-649. http://dx.doi.org/10.1579/0044-7447(2007)36[639: CHANS]2.0.CO;2

Liu, J., T. Dietz, S. R. Carpenter, M. Alberti, C. Folke, E. Moran, A. N. Pell, P. Deadman, T. Kratz, J. Lubchenco, E. Ostrom, Z. Ouyang, W. Provencher, C. L. Redman, S. H. Schneider, and W. W. Taylor. 2007b. Complexity of coupled human and natural systems. Science 317(5844):1513-1516. http://dx.doi.org/10.1126/ science.1144004

Liu, J., V. Hull, M. Batistella, R. DeFries, T. Dietz, F. Fu, T. Hertel, R. C. Izaurralde, E. Lambin, S. Li, L. Martinelli., W. J. McConnell, E. F. Moran, R. Naylor, Z. Ouyang, K. R. Polenske, A. Reenberg, G. de Miranda Rocha, C. S. Simmons, P. H. Verburg, P. M. Vitousek, F. Zhang, and C. Zhu. 2013. Framing sustainability in a telecoupled world. Ecology and Society 18 (2):26. http://dx.doi.org/10.5751/ES-05873-180226

Liu, J., H. Mooney, V. Hull, S. J. Davis, J. Gaskell, T. Hertel, J. Lubchenco, K. C. Seto, P. Gleick, C. Kremen, and S. Li. 2015. Systems integration for global sustainability. Science 347 (6225):1258832. http://dx.doi.org/10.1126/science.1258832

Liu, J., W. Yang, and S. Li. 2016. Framing ecosystem services in the telecoupled Anthropocene. Frontiers in Ecology and the Environment 14(1):27-36. http://dx.doi.org/10.1002/16-0188.1

Machlis, G. E., J. E. Force, and W. R. Burch, Jr. 1997. The human ecosystem part I: the human ecosystem as an organizing concept in ecosystem management. Society and Natural Resources 10 (4):347-367. http://dx.doi.org/10.1080/08941929709381034

Marshall, K. N., P. S. Levin, T. E. Essington, L. E. Koehn, L. G. Anderson, A. Bundy, C. Carothers, F. Coleman, L. R. Gerber, J. H. Grabowski, E. Houde, O. P. Jensen, C. Möllmann, K. Rose, J. N. Sanchirico, and A. D. M. Smith. 2018. Ecosystem-based fisheries management for social-ecological systems: renewing the focus in the United States with next generation fishery ecosystem plans. Conservation Letters 11(1):1-7. http://dx.doi.org/10.1111/ $\underline{\text { conl.12367 }}$

Max-Neef, M. A. 2005. Foundations of transdisciplinarity. Ecological Economics 53(1):5-16. http://dx.doi.org/10.1016/j. ecolecon.2005.01.014

McCord, P., J. Dell'Angelo, E. Baldwin, and T. Evans. 2016. Polycentric transformation in Kenyan water governance: a dynamic analysis of institutional and social-ecological change. Policy Studies Journal 45(4):633-658. http://dx.doi.org/10.1111/ psj. 12168

McGinnis, M. D., and E. Ostrom. 2014. Social-ecological system framework: initial changes and continuing challenges. Ecology and Society 19(2):30. http://dx.doi.org/10.5751/ES-06387-190230

McHale, M. R., D. N. Bunn, S. T. A. Pickett, and W. Twine. 2013. Urban ecology in a developing world: why advanced socioecological theory needs Africa. Frontiers in Ecology and the Environment 11(10):556-564. http://dx.doi.org/10.1890/120157

Mehta, L., G. J. Veldwisch, and J. Franco. 2012. Introduction to the special issue: water grabbing? Focus on the (re) appropriation of finite water resources. Water Alternatives 5(2):193-207. [online] URL: http://www.water-alternatives.org/index.php/volume5/v5issue2/165a5-2-1/file

Millennium Ecosystem Assessment (MEA). 2005. Millennium ecosystem assessment. Ecosystems and human well-being: synthesis. World Resources Institute, Washington, D.C., USA. [online] URL: https://www.millenniumassessment.org/documents/ document.356.aspx.pdf

Morton, J. F. 2007. The impact of climate change on smallholder and subsistence agriculture. Proceedings of the National Academy of Sciences 104(50):19680-19685. http://dx.doi.org/10.1073/ pnas.0701855104

Nagendra, H., and E. Ostrom. 2014. Applying the socialecological system framework to the diagnosis of urban lake commons in Bangalore, India. Ecology and Society 19(2):67. http://dx.doi.org/10.5751/ES-06582-190267

Ostrom, E. 2007. A diagnostic approach for going beyond panaceas. Proceedings of the National Academy of Sciences 104 (39):15181-15187. http://dx.doi.org/10.1073/pnas.0702288104

Ostrom, E. 2009. A general framework for analyzing sustainability of social-ecological systems. Science 325 (5939):419-422. http://dx.doi.org/10.1126/science.1172133

Pace, M. L., and J. A. Gephart. 2017. Trade: a driver of present and future ecosystems. Ecosystems 20(1):44-53. http://dx.doi. org/10.1007/s10021-016-0021-Z 
Pelletier, D., M.-É. Lapointe, M. A. Wulder, J. C. White, and J. A. Cardille. 2017. Forest connectivity regions of Canada using circuit theory and image analysis. PloS One 12(2):e0169428. http://dx.doi.org/10.1371/journal.pone.0169428

Pickett, S. T. A., M. L. Cadenasso, J. M. Grove, C. H. Nilon, R. V. Poyat, W. C. Zipperer, and R. Costanza. 2001. Urban ecological systems: linking terrestrial ecological, physical, and socioeconomic components of metropolitan areas. Annual Review of Ecology and Systematics 32:127-157. http://dx.doi.org/10.1146/annurev. ecolsys.32.081501.114012

Pittman, J., and D. Armitage. 2017. How does network governance affect social-ecological fit across the land-sea interface? An empirical assessment from the Lesser Antilles. Ecology and Society 22(4):5. http://dx.doi.org/10.5751/ES-09593-220405

Prell, C., L. Sun, K. Feng, J. He, and K. Hubacek. 2017. Uncovering the spatially distant feedback loops of global trade: a network and input-output approach. Science of the Total Environment 586:401-408. http://dx.doi.org/10.1016/j. scitotenv.2016.11.202

Raudsepp-Hearne, C., G. D. Peterson, M. Tengö, E. M. Bennett, T. Holland, K. Benessaiah, G. K. MacDonald, and L. Pfeifer. 2010. Untangling the environmentalist's paradox: why is human well-being increasing as ecosystem services degrade? BioScience 60(8):576-589. http://dx.doi.org/10.1525/bio.2010.60.8.4

Rissman, A. R., and S. Gillon. 2017. Where are ecology and biodiversity in social-ecological systems research? A review of research methods and applied recommendations. Conservation Letters 10(1):86-93. http://dx.doi.org/10.1111/conl.12250

Rocha, J., J. Yletyinen, R. Biggs, T. Blenckner, and G. Peterson. 2015. Marine regime shifts: drivers and impacts on ecosystems services. Philosophical Transactions of the Royal Society B 370 (1659):20130273. http://dx.doi.org/10.1098/rstb.2013.0273

Rulli, M. C., A. Saviori, and P. D'Odorico. 2013. Global land and water grabbing. Proceedings of the National Academy of Sciences 110(3):892-897. http://dx.doi.org/10.1073/pnas.1213163110

Sayles, J. S., and J. A. Baggio. 2017. Social-ecological network analysis of scale mismatches in estuary watershed restoration. Proceedings of the National Academy of Sciences 114(10):E1776E1785. http://dx.doi.org/10.1073/pnas.1604405114

Schlüter, M., R. R. J. McAllister, R. Arlinghaus, N. Bunnefeld, K. Eisenack, F. Hölker, E. J. Milner-Gulland, B. Müller, E. Nicholson, M. Quaas, and M. Stöven. 2012. New horizons for managing the environment: a review of coupled social-ecological systems modeling. Natural Resource Modeling 25(1):219-272. http://dx.doi.org/10.1111/j.1939-7445.2011.00108.x

Teddlie, C., and F. Yu. 2007. Mixed methods sampling: a typology with examples. Journal of Mixed Methods Research 1(1):77-100. http://dx.doi.org/10.1177/2345678906292430

Thiel, A., M. E. Adamseged, and C. Baake. 2015. Evaluating an instrument for institutional crafting: how Ostrom's socialecological systems framework is applied. Environmental Science and Policy 53:152-164. http://dx.doi.org/10.1016/j.envsci.2015.04.020

Thomas, K. A. 2017. The river-border complex: a borderintegrated approach to transboundary river governance illustrated by the Ganges River and Indo-Bangladeshi border. Water International 42(1):34-53. http://dx.doi.org/10.1080/0250$\underline{8060.2016 .1247236}$

Turner, M. G., V. H. Dale, and R. H. Gardner. 1989. Predicting across scales: theory development and testing. Landscape Ecology 3(3-4):245-252. http://dx.doi.org/10.1007/BF00131542

Turner, B. L., II, K. J. Esler, P. Bridgewater, J. Tewksbury, N. Sitas, B. Abrahams, F. S. Chapin, III, R. R. Chowdhury, P. Christie, S. Diaz, P. Firth, C. N. Knapp, J. Kramer, R. Leemans, M. Palmer, D. Pietri, J. Pittman, J. Sarukhán, R. Shackleton, R. Seidler, B. van Wilgen, and H. Mooney. 2016. Socio-environmental systems (SES) research: what have we learned and how can we use this information in future research programs? Current Opinion in Environmental Sustainability 19:160-168. http://dx.doi.org/10.1016/ j.cosust.2016.04.001

Turner, B. L., II, R. E. Kasperson, P. A. Matson, J. J. McCarthy, R. W. Corell, L. Christensen, N. Eckley, J. X. Kasperson, A. Luers, M. L. Martello, C. Polsky, A. Pulsipher, and A. Schiller. 2003. A framework for vulnerability analysis in sustainability science. Proceedings of the National Academy of Sciences 100 (14):8074-8079. http://dx.doi.org/10.1073/pnas. 1231335100

Ulibarri, N., and T. A. Scott. 2017. Linking network structure to collaborative governance. Journal of Public Administration Research and Theory 27(1):163-181. http://dx.doi.org/10.1093/ jopart/muw041

van Vliet, J., N. R. Magliocca, B. Büchner, E. Cook, J. M. R. Benayas, E. C. Ellis, A. Heinimann, E. Keys, T. M. Lee, J. Liu, O. Mertz, P. Meyfroidt, M. Moritz, C. Poeplau, B. E. Robinson, R. Seppelt, K. C. Seto, and P. H. Verburg. 2016. Meta-studies in land use science: current coverage and prospects. Ambio 45(1):15-28. http://dx.doi.org/10.1007/s13280-015-0699-8

Vogt, J. M., G. B. Epstein, S. K. Mincey, B. C. Fischer, and P. McCord. 2015. Putting the "E" in SES: unpacking the ecology in the Ostrom social-ecological system framework. Ecology and Society 20(1):55. http://dx.doi.org/10.5751/ES-07239-200155

Ziegler, J. P., E. J. Golebie, S. E. Jones, B. C. Weidel, and C. T. Solomon. 2017. Social-ecological outcomes in recreational fisheries: the interaction of lakeshore development and stocking. Ecological Applications 27(1):56-65. http://dx.doi.org/10.1002/ eap.1433 
Appendix 1. Research method for the analysis of empirical applications of frameworks

Our search for articles that empirically applied each framework was conducted as follows:

1. Each foundational article was searched for in Web of Science Core Collection. For frameworks with more than one foundational article, we focused on the first article listed for the citation analysis. These included Holling (2001) for Resilience, de Groot et al. (2002) for IAES, Liu et al. (2007b) for CHNS, and Ostrom (2007) for SESF.

2. Once the title of the foundational article was entered, a list of all articles citing the manuscript was returned. The total number of articles was recorded.

3. To limit this search to only "socio-ecological" or "socio-environmental" papers, results were refined by entering keywords such as "socio-environmental", "socio-ecological", "coupled human natural system", etc.

4. The refined list of articles was regarded as the sample of SE research referencing the framework in any way.

5. All abstracts of manuscripts from this refined list were reviewed and the entire article received a cursory review to assess whether or not the framework was applied. If it was applied, the following information was recorded:

a. The SE system domain of the research (e.g., watershed management, smallholder farming system, fishery, etc.).

b. The location of the system under investigation.

Table A1.1. Citation metadata

\begin{tabular}{llrrr}
\hline \hline Framework & Foundational article & $\begin{array}{r}\text { Total } \\
\text { citations }\end{array}$ & $\begin{array}{r}\text { Refined } \\
\text { citations }\end{array}$ & $\begin{array}{r}\text { Citations with } \\
\text { empirical } \\
\text { application }\end{array}$ \\
\hline HEF & Machlis et al. (1997) & 100 & 37 & 99 \\
Resilience & Holling (2001) & 873 & 298 & 42 \\
IAES & de Groot et al. (2002) & 1053 & 111 & 10 \\
TVUL & Turner et al. (2003) & 997 & 263 & 24 \\
CHNS & Liu et al. (2007b) & 856 & 71 & 31 \\
\hline SESF & Ostrom (2007) & 650 & 77 & \\
\hline
\end{tabular}


Appendix 2. Framework visualizations

Figure A2.1. Human Ecosystem Framework (HEF)

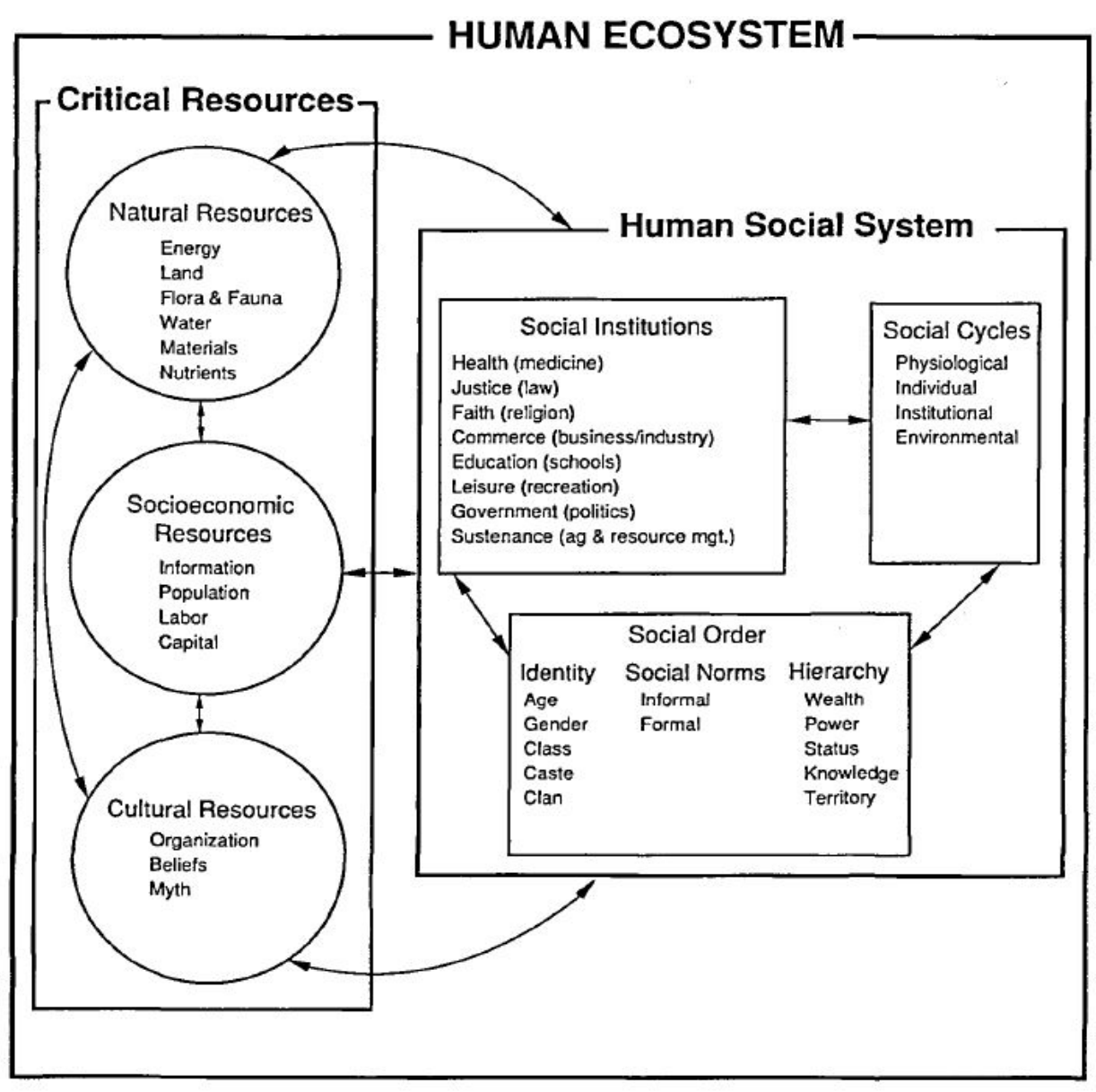

(Source: Machlis et al. 1997:352) 
Figure A2.2. Resilience

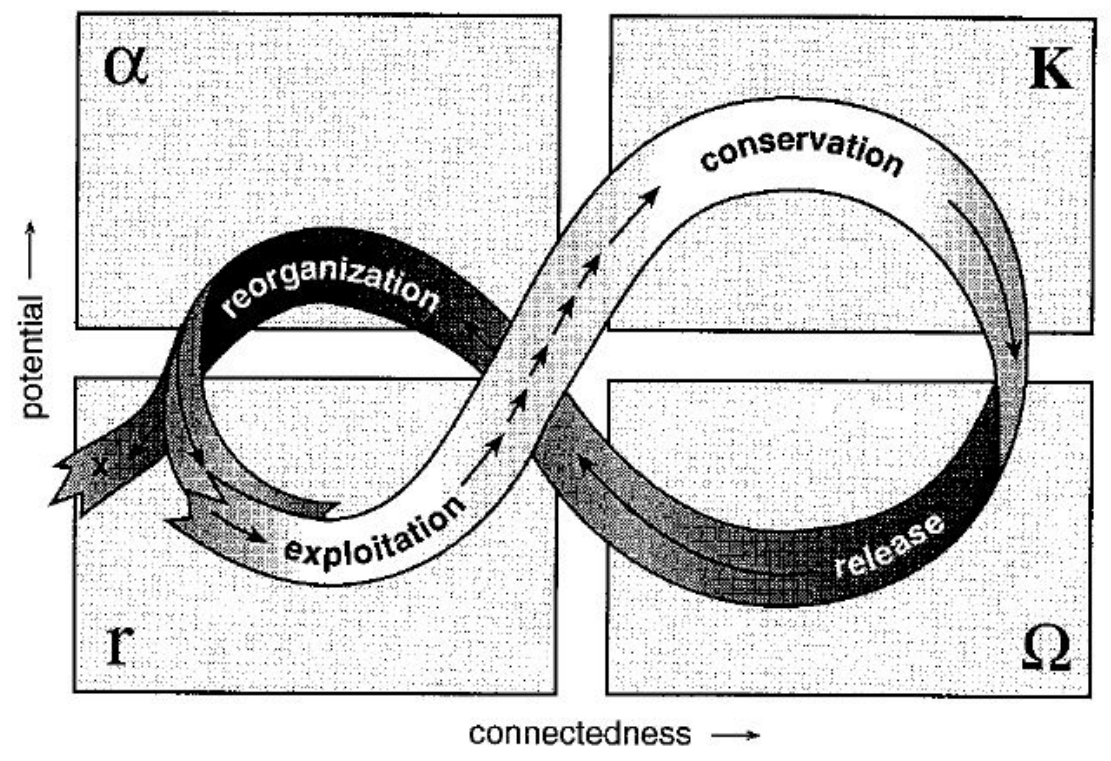

(Source: Holling 2001:394) 
Figure A2.3. Integrated Assessment of Ecosystem Services (IAES)

a.

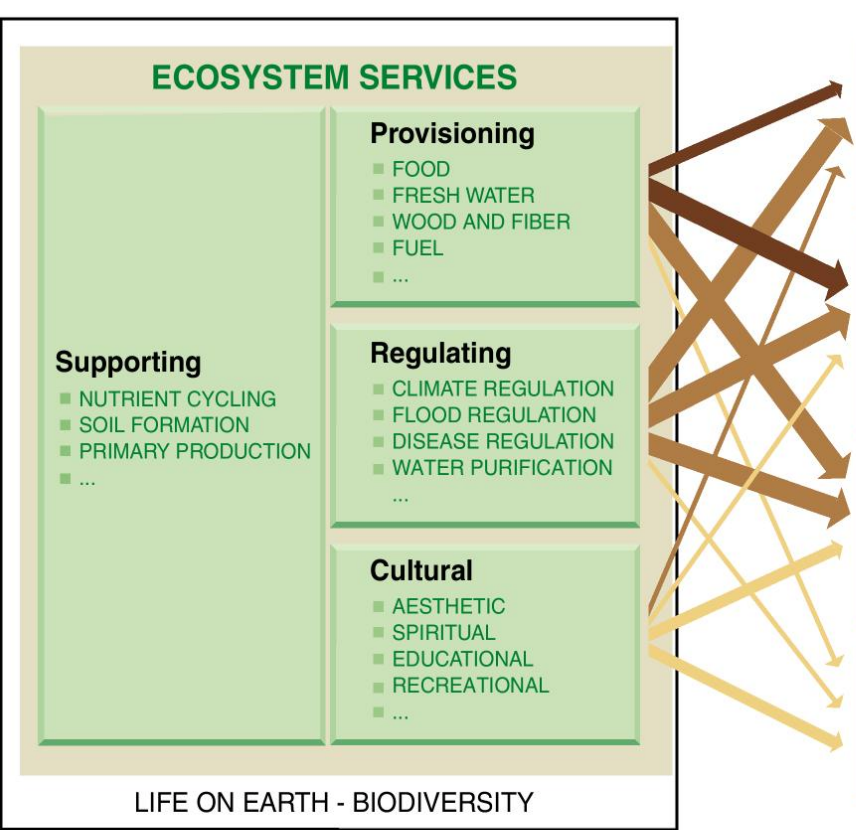

\section{CONSTITUENTS OF WELL-BEING}

\section{Security}

- PERSONAL SAFETY

- SECURE RESOURCE ACCESS

SECURITY FROM DISASTERS

Basic material

for good life

ADEQUATE LIVELIHOODS

- SUFFICIENT NUTRITIOUS FOOD

SHELTER

ACCESS TO GOODS

\section{Health}

$=$ STRENGTH

- FEELING WELL

ACCESS TO CLEAN AIR

AND WATER

\section{Good social relations}

- SOCIAL COHESION

- MUTUAL RESPECT

- ABILITY TO HELP OTHERS

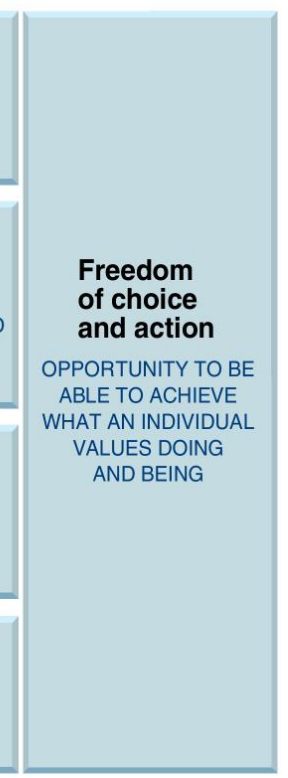

Source: Millennium Ecosystem Assessment

ARROW'S COLOR

Potential for mediation by socioeconomic factors

Low

Medium

High
ARROW'S WIDTH

Intensity of linkages between ecosystem

services and human well-being

Weak

Medium

Strong

(Source: MEA 2005:vi) 
b.

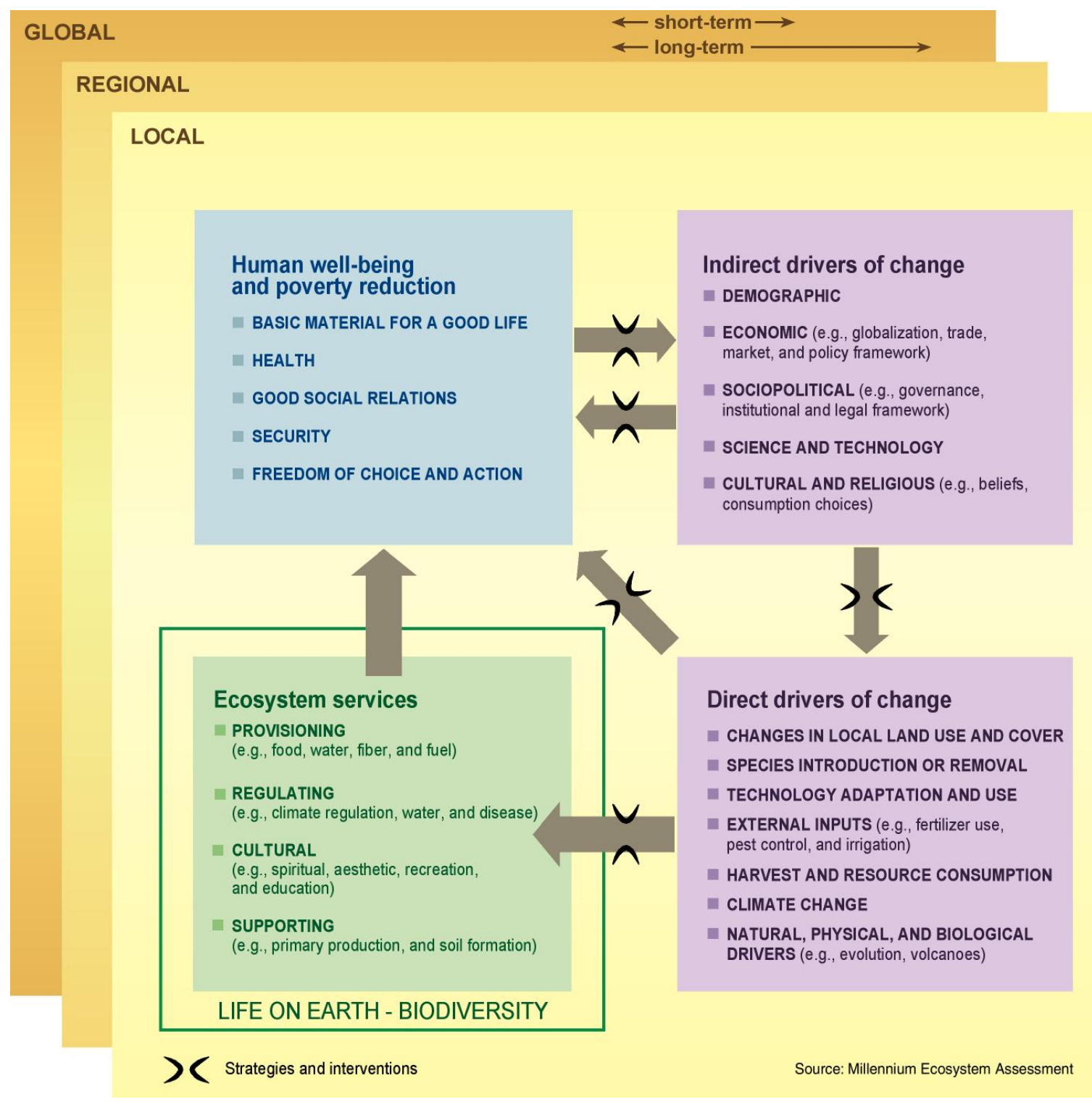

(Source: MEA 2005:vil) 
Figure A2.4. Vulnerability Framework (TVUL)

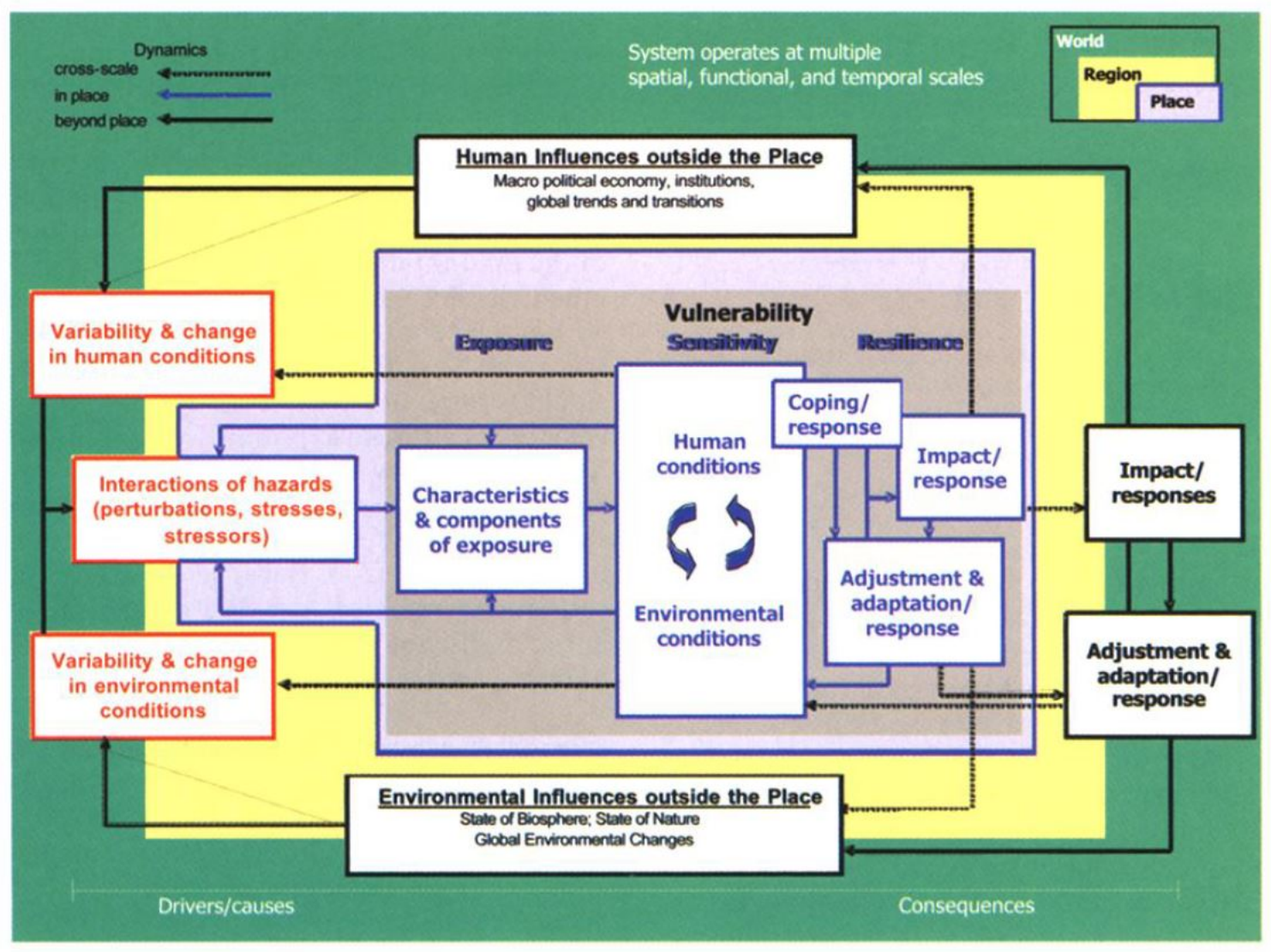

(Source: Turner et al. 2003:8076) 
Figure A2.5. Social Ecological Systems Framework (SESF)

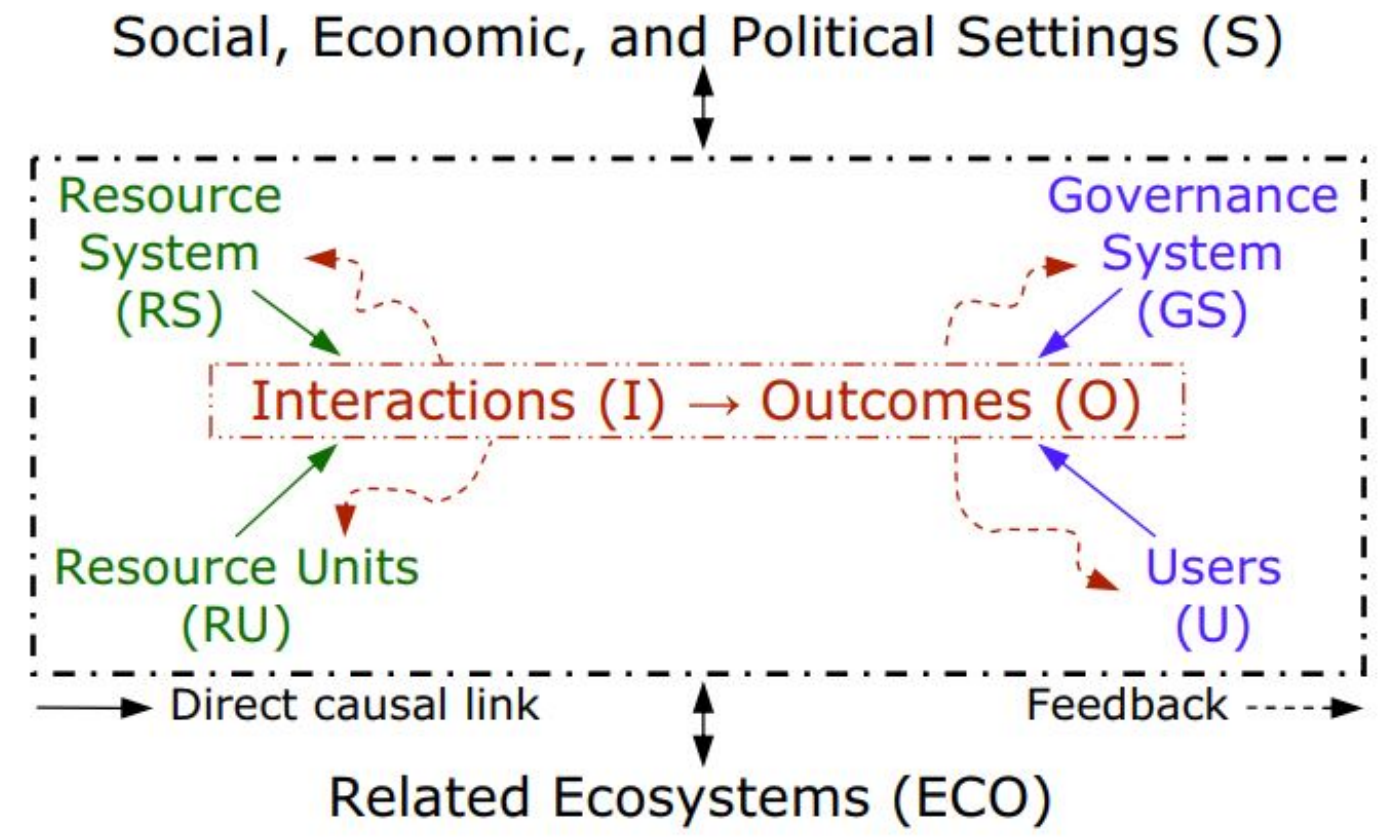

(Source: Ostrom 2007:15182)

NB: There is no visualization for the Coupled Human-Natural Systems approach. 